\title{
Work Characteristics or Workers' Characteristics? An Input-Process-Output Perspective on Informal Workplace Learning of Blue-Collar Workers
}

\author{
Julian Decius $^{1}$ (D) Niclas Schaper ${ }^{1}$ D $\cdot$ Andreas Seifert $^{1}$ (D)
}

Received: 13 February 2020 / Accepted: 29 January 2021 / Published online: 12 March 2021

(c) The Author(s) 2021

\begin{abstract}
We investigated informal workplace learning (IWL) within an under-researched target group: blue-collar workers. IWL is particularly important for these workers because of learning barriers to participation in formal training. Based on meta-analytical conceptualizations and findings, we developed a conceptual framework of antecedents, processes, and learning outcomes of IWL among blue-collar workers (APO framework), following an input-process-output perspective. The results of our structural equation model analysis with $N=702$ blue-collar workers from small and medium-sized businesses provided support for seven of eight hypotheses: Personal antecedents, namely curiosity, learning goal orientation, and self-directed learning orientation were positively related to IWL; organizational antecedents, namely social support-containing supervisor support, coworker support, and error-related learning climate-and, surprisingly, time pressure were positively related to IWL; IWL was positively related to three learning outcomes, namely job involvement, newly acquired competency, and organizational citizenship behavior. The findings establish a basis for future longitudinal studies and theory building in workplace learning research, and they provide managers in organizations with guidance to promote IWL.
\end{abstract}

Keywords Informal workplace learning · Antecedents $\cdot$ Learning outcomes $\cdot$ Inputprocess-output model $\cdot$ Blue-collar workers $\cdot$ Small and medium-sized businesses

Informal learning is the oldest form of workplace learning. Since humans have been working - from Stone Age through Medieval times to present day-they have learned by reflection, feedback or simply by completing their work tasks. Informal

Julian Decius

julian.decius@uni-paderborn.de

1 Institute of Psychology, University of Paderborn, Warburger Strasse 100, 33098 Paderborn, Germany 
workplace learning (IWL) is defined as a non-curricular learning type which takes place outside formally-designated learning contexts, and which is predominantly self-directed, intentional, and field-based (Cerasoli et al. 2018). IWL accounts for most of workplace learning, although it is hardly possible to state an exact percentage (Clardy 2018).

We study IWL in a context domain for which IWL is an essential part of workplace learning: blue-collar workers. Blue-collar workers mostly work in small and medium-sized businesses (SMBs), defined as having fewer than 250 employees and less than 50 million euros in annual revenue (cf. European Union 2017). SMBs cannot invest as much time and financial resources in formal personnel development as larger enterprises (Abel and Wagner 2017; Coetzer et al. 2017; Decius and Schaper 2017). Furthermore, learning in SMBs is characterized by the sudden need for workers to learn and to apply what they have learned directly (Jeong et al. 2018b). In such cases, it is challenging for SMBs to release employees to participate in (external) formal trainings, as it is more difficult for SMBs than for larger companies to compensate for the temporary absence of staff in often strictly planned work processes (Blings 2008).

Continuing education and learning ${ }^{1}$ for blue-collar workers suffers from these constraints. Lundkvist and Gustavsson (2018) stated that SMBs "often find it difficult to upgrade workers' skills and competencies because vocational education or training is seldom demand driven or customized for [SMB] contexts" (p. 46). The approaches and intervention policies developed for large enterprises are difficult to transfer to SMBs (Wong and Aspinwall 2004). Although blue-collar workers mainly work in the manufacturing sector-where tasks tend to be of low complexity with a high degree of repetitive work routines-workers need a lot of experience-based knowledge for an effective and efficient work execution (Hirsch-Kreinsen and Ten Hompel 2017). Learning and development is therefore necessary. In addition to the aforementioned resource limitations of enterprises, personal learning barriers also stand in the way of formal training. In the target group of blue-collar workers, these barriers include low vocational qualification levels, bad reputation of formal trainings because of previous school experiences, and language restrictions due to high migration rates (Abel et al. 2016; Bimrose et al. 2016; Galiläer and Wende 2008; Illeris 2006; Kyndt et al. 2013b; Ittermann et al. 2011; Tippelt et al. 2004). Could IWL be part of the solution instead of formal training? One could expect that for bluecollar jobs IWL would play a minor role because they are largely prescribed and line driven, but the opposite is the case: IWL is less affected by the mentioned learning barriers than formal learning and takes place in an authentic setting which facilitates learning transfer (Billett 1995). IWL therefore is an important supplement to formal training among blue-collar workers (Decius et al. 2019).

But which organizational conditions and which personal characteristics are beneficial to IWL of blue-collar workers? Despite the important role of SMBs for the economy, research on learning conditions and outcomes in SMBs is scarce

\footnotetext{
1 In the context of this study we use the term "learning" for any work-related training and development activities of employees. However, blue-collar workers themselves often associate "learning" with formal learning activities only (Kyndt et al. 2013b).
} 
(Kock and Ellström 2011; Kortsch and Kauffeld 2019). Especially blue-collar workers are under-researched; recent studies on IWL have dealt with other target groups, e.g., school teachers (Bernadette Van Rijn et al. 2013), managers (Noe et al. 2013), police inspectors (Janssens et al. 2017), and nurses (Kyndt et al. 2016b). However, due to the special learning barriers mentioned above for bluecollar workers (especially in SMBs), we assume that these workers need different learning conditions: Similar basic variables and constructs could be relevant for IWL, but with a different weighting and prioritization.

Researchers have recently called for the development of clear sets of personal and organizational IWL antecedents as well as the analysis of learning consequences within a nomological network (Cerasoli et al. 2018; Jeong et al. 2018a; Noe et al. 2014). As far as we know, however, there is still no conceptual framework taking into account the specific learning conditions and learning outcomes of the crucial target group of blue-collar workers in a holistic way. In our study, we thus apply the input-process-output model (I-P-O model, e.g., Bushnell 1990; Ilgen et al. 2005) to the individual learning context. The basic assumptions of the I-P-O model are that an input leads to a process and that this process yields an output. This model approach is consistent with the 3-P Model of Workplace Learning, which comprises the components presage, process and product (Tynjälä, 2013).

Within the I-P-O model, the organizational and personal antecedents represent the inputs (or presage), IWL constitutes the learning process, and the learning outcomes depict the output (or product). We use the meta-analytical framework of Cerasoli et al. (2018) to develop the Antecedents, Processes, and Outcomes Framework of IWL for Blue-collar Workers (APO framework). The APO framework provides specific hypotheses on the relationship of IWL with antecedents and outcomes. Although the meta-analysis of Cerasoli et al. represents an important milestone in IWL research, it inevitably has relied on initial studies that operationalized IWL in an inconsistent manner and in most cases without conceptual basis. Acknowledging this shortcoming, we rely on the Octagon Model of IWL by Decius et al. (2019) for IWL conceptualization. In addition to the meta-analysis of Cerasoli et al. we include further cross-sectional studies that do not contain predictors for learning behavior but for learning intentions of blue-collar workers (e.g., Kyndt et al. 2011, 2013a, b).

With our quantitative survey study among blue-collar workers in German SMBs we investigate the assumptions resulting from the APO Framework. In detail, we examine the following research questions relevant to science and practice: (1) Which of the personal constructs curiosity, learning goal orientation, and self-directed learning orientation and which of the organizational constructs social support (i.e., supervisor support, coworker support, and error-related learning climate) and time pressure are relevant antecedents of informal learning? (2) How is the relevance of the three mentioned personal constructs as antecedents of informal learning compared to the relevance of the two mentioned organizational constructs? (3) Which of the constructs job involvement, newly acquired competence, and organizational citizenship behavior are relevant as learning outcomes of informal learning? Our study provides initial indications to answer these questions, although we are aware that 
relative importance can be shown only to a limited extent in a non-experimental, cross-sectional approach.

Studies that simultaneously test a full model of antecedents, IWL, and outcomes are lacking (Cerasoli et al. 2018) — thus, we follow a holistic approach. Using structural equation technique, our study contributes to the analysis of covariation between the constructs relevant for IWL. This step is regarded as a strength of crosssectional research designs and can set the stage for further longitudinal studies that might explain causality (Spector 2019). We therefore address the correlational part of the observational-correlational-experimental loop (Rosenshine and Furst 1973) in learning research: "Observational studies can lead to correlational ones and correlational ones to semi-experimental or perhaps even experimental ones" (DeKeyser and Botana 2019, p. 4). To our knowledge, this study is the first to simultaneously analyze the relationships between antecedents and outcomes with IWL among bluecollar workers in a holistic empirical model.

Our contribution to IWL research is to establish a specific framework for IWL of blue-collar workers and to empirically test this framework for the first time. For organizational practice, managers especially of SMBs can learn from the results where the best leverage might be to promote IWL and to attain its outcomes within the enterprise. This is particularly important in view of limited resources when managers must decide which intervention to implement first in order to support employees' development. In the following, we present the current state of operationalizing IWL. We then introduce the APO framework and define the constructs we examine.

\section{Theoretical Background of Informal Workplace Learning}

\section{Operationalizing Informal Workplace Learning}

For a long time, researchers have not agreed on the components belonging to IWL or how they should be arranged in a conceptual framework. The consensus has been merely that IWL is the counterpart to formal learning on a continuum. However, Tannenbaum et al. (2010) presented a dynamic model of IWL, comprising four components: Intent to learn, experience/action, feedback, and reflection. The model is considered dynamic because all components can trigger each other and can be passed through once or several times in any order during the learning sequence. The learning is most effective if all four factors are included in the learning process (Tannenbaum et al. 2010). The authors themselves indicated that the components may be subdivided even more in detail. Therefore, Decius et al. (2019) extended the dynamic model from four to eight components by separating each component into two sub-factors. In their octagon model, experience/action was divided into trying/ applying own ideas and model learning; feedback into direct feedback and vicarious feedback; reflection into anticipatory reflection and subsequent reflection; intent to learn into intrinsic intent to learn and extrinsic intent to learn. The octagon model is a multilevel model with a core factor IWL, four components at the first level, and eight components at the second level. Building on the conceptual basis of the octagon model, Decius et al. (2019) provided a measure for the operationalization of 
IWL. We decided to use this measure because it was developed for the target group of blue-collar workers and has a theoretical foundation with the octagon model, unlike other measures being developed in rather exploratory processes (e.g., Choi and Jacobs 2011; Froehlich et al. 2017; Grosemans et al. 2020; Kortsch et al. 2019; Noe et al. 2013; Wolfson et al. 2018).

\section{Development of the Antecedents, Processes and Outcomes Framework of IWL for Blue-Collar Workers}

We based the development of our framework of antecedents, processes and outcomes of IWL for blue-collar workers (cf. Table 1) on the meta-analytical, nontarget group specific framework of Cerasoli et al. (2018). The top level of their framework, specificity level 1, contains the broad subdivision into personal and organizational antecedents and outcomes. Specificity level 2 provides a more detailed classification of categories, which are further subdivided at specificity level 3 (for antecedents only, not for outcomes). At specificity level 3, Cerasoli et al. (2018) sometimes named example constructs that have been investigated by previous research.

In our study, unlike a meta-analysis, we cannot include all possible constructs ever investigated in research. Developing the APO framework for blue-collar workers, we must be selective-as our aim is to examine the simultaneous relationships between antecedents, IWL, and learning outcomes within an integrative targetgroup specific model. However, even if the meta-analysis by Cerasoli et al. did not provide any insight into the relationships between single constructs (e.g., curiosity) and IWL, it gave us a conceptual framework, assuming relationships between specificity levels categories (e.g., personality/propensity factors as a summarized domain which also contains curiosity) and IWL.

At specificity level 2 of the Cerasoli-framework, personal antecedents are divided into individual predispositions and demographics (i.e., age, education, sex, income, rank/tenure, experience, marital status). However, Cerasoli et al. (2018, p. 207) stated that "participants' demographics [rarely have] been treated as substantive predictors of [informal learning behaviors]; they are typically considered as simply potential covariates (Berg and Chyung 2008)". Furthermore, because we did not see any theoretical justification and the meta-analysis did not reveal a significant relation of the overall demographic category with informal learning, we do not include the demographic variables in the APO framework. ${ }^{2}$ Cerasoli et al. (2018) subdivided individual predispositions at specificity level 3 into personality/propensity factors and general learning-related motives. For covering personality/propensity factors we incorporate curiosity into the APO framework; for covering general learningrelated motives we consider learning goal orientation and self-directed learning orientation. Both were mentioned as example constructs in the Cerasoli-framework as well.

\footnotetext{
${ }^{2}$ Since we collected demographic variables in our survey (see sample description), we nevertheless checked the connections between demography and IWL to be on the safe side. We found no significant path coefficients in our model.
} 


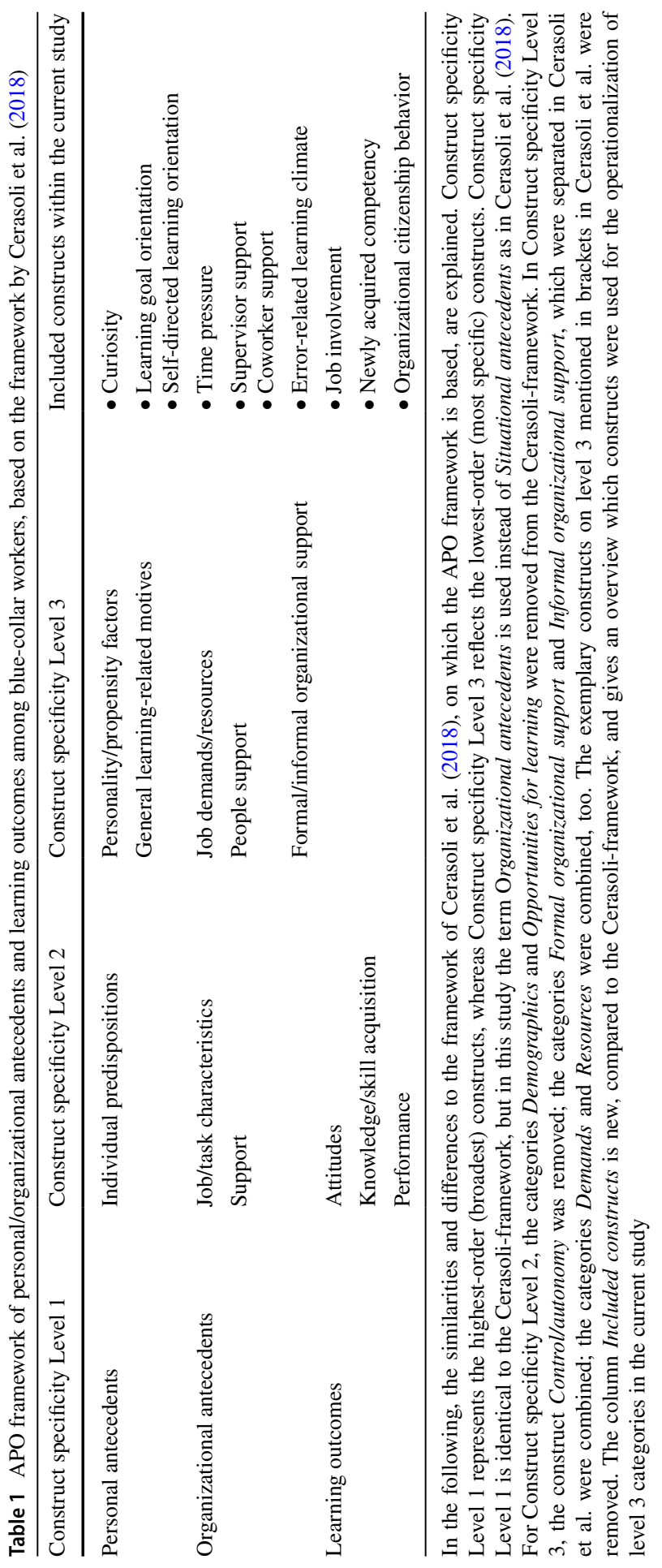


Organizational antecedents at specificity level 2 of the Cerasoli-framework are divided into job/task characteristics (at specificity level 3, i.e., demands, resources, control/autonomy), support (i.e., people, formal, informal support), and opportunities for learning (i.e., potential for new learning, lower workload, time). In the domain of support, we use the constructs supervisor support and coworker support for people support and cover formal/informal organizational support by including error-related learning climate as organizational antecedent. In the meta-analysis of Cerasoli et al. (2018), the domain opportunities for learning as an overall category had no significant relationship with informal learning, thus we do not include the category as a whole. However, for conceptual reasonsbecause the time component plays an important role in industrial work-we cover the facets time and lower workload of the domain opportunities for learning by including the opponent construct time pressure, which we regard as job/task characteristic at specificity level 3. We do not include Control/autonomy because it is less relevant for the target group: Blue-collar workers often act strictly according to external instructions and execute work orders-the organizations usually do not provide greater scope for workers' own decisions and actions (Decius et al. 2019; Huang 2011).

Learning outcomes can be defined as sustainable changes in knowledge, skills, and attitudes as a result of engaging in learning activities (Kraiger et al. 1993). Similarly, Cerasoli et al. (2018) subdivided the learning outcomes at specificity level 2 into attitudes (i.e., positive general work attitudes), knowledge/skill acquisition (e.g., knowledge acquisition, core skills), and performance (e.g., project performance). We follow this division in the APO framework and cover attitudes with the construct job involvement. For knowledge/skill acquisition we provide the construct newly acquired competency, and for performance we select organizational citizenship behavior (OCB). In the following, we present the APO framework constructs more in detail and underline our selection of constructs based on three criteria: (a) theoretical relevance of the construct in the IWL literature with special focus on blue-collar workers (if available), (b) practical relevance of the construct for blue-collar work (especially based on the research experiences and target group interviews of the first author and the second author in a former research project with blue-collar workers in SMBs), and (c) empirical evidence of the construct with IWL in previous research with special focus on blue-collar workers (if available). In addition to our own literature research, we also included the review studies by Baert (2018), Kyndt and Baert (2013), and Tannenbaum et al. (2010) to provide practical relevance and empirical evidence.

\section{Personal Antecedents of IWL}

Curiosity Curiosity refers to the desire for "recognizing, embracing, and seeking out knowledge and new experiences" (Kashdan et al. 2009, p. 988). Thus, curiosity is an important requirement for learning processes, to acquire new skills and expand one's capabilities. Individuals with high curiosity pay greater attention to tasks or 
activities, handle and remember information better and persist longer in work tasks until goals are reached (Silvia 2006).

But why might curiosity be important for learning of blue-collar workers? Bluecollar workers are often not systematically supported in their learning process. Partly because of the often-repetitive nature of the work tasks and low chances of promotion, workers sometimes have problems to motivate themselves to learn (cf. Kyndt et al. 2013a). However, employees who are interested in the work process and are curious to know how their work tasks can be completed in an easier, quicker, or qualitatively better way, learn new skills even without systematic support. Curiosity seems to be a facilitator of workplace learning (Hicks et al. 2007). For bluecollar workers, curiosity might even be more crucial than for white-collar workers, because the internal desire for knowledge could counterbalance the effect of the working environment, which may be poor in stimuli for learning.

Empirically, Reio and colleagues have established curiosity as a predictor of workplace learning among employees in the service industry (Reio and Callahan 2004; Reio and Wiswell 2000). Moon and $\mathrm{Na}$ (2009) found a positive link between curiosity and IWL in the working context of SMBs. In view of these conceptual and empirical indications, we assume that curiosity is a positive antecedent of bluecollar workers' IWL.

\section{Hypothesis 1: Curiosity is positively related to IWL.}

Learning Goal Orientation Goal-setting theory (Locke and Latham 1990, 2002) has underlined the importance of specific, difficult, but achievable goals for performance enhancement. Goal setting also plays an essential role in learning-but not every individual has the same drive to do so. In this context, learning goal orientation (LGO) is characterized by the willingness to engage in challenging activities to improve one's own skills and competencies and by the tendency to use one's past performance as a standard for evaluating current performance (Button et al. 1996).

For professional development it is crucial that blue-collar workers also have to work with previously unknown machines or compare their actual work performance (e.g., quality and number of pieces) with their previous performance. Some workers set learning goals, such as a low rejection rate or a high assembly speed. These goals help them to obtain feedback and monitor their own performance to improve their skills in the long term.

Empirical findings showed the high importance of LGO for participation in learning and development activities (Brett and VandeWalle 1999; Hurtz and Williams 2009; Klein et al. 2006; Matzler and Mueller 2011; Orvis and Leffler 2011). Regarding IWL, research found positive links between LGO and various informal learning activities (Choi and Jacobs 2011; Noe et al. 2017; Schulz and Stamov Roßnagel 2010). Furthermore, LGO is accompanied by a tendency to pay attention to feedback — which is a core component of IWL-as being beneficial for learning and to actively seek feedback on one's own performance 
(VandeWalle 2003). We thus assume that LGO is a positive antecedent of bluecollar workers' IWL.

Hypothesis 2: Learning goal orientation is positively related to IWL.

Self-Directed Learning Orientation According to Raemdonck et al. (2014b), selfdirected learning orientation (SDLO) is a tendency to take an active and self-starting approach to learning activities and situations, and to persist in overcoming barriers and setbacks concerning the work-related learning process. Employees with a high SDLO identify learning opportunities and show learning initiative to undertake learning activities (Gijbels et al. 2010; Gijbels et al. 2012). The sequence model of self-regulated learning by Schmitz and Wiese (2006) assumed further that learners in the self-directed learning process pass through a circle of pre-action, action, and post-action phases. SDLO primarily addresses the personal components affect, goals, motivation, and self-efficacy contained in the pre-action phase.

In the daily work of blue-collar workers, opportunities for IWL are scarce, as work is characterized by many simple and routine tasks. This makes it even more important for the workers to quickly recognize sporadic learning opportunities, to grasp the learning initiative themselves and to develop it in a self-directed manner. In the long term, the informally learnt skills may enable workers to climb the internal career ladder.

Previous studies have shown consistently that SDLO is highly correlatedbetween $r=.49$ and .61—with informal learning (Gijbels et al. 2010, 2012; Raemdonck et al. 2014a). Furthermore, SDLO is a sound predictor of learning intentions (Kyndt et al. 2011, 2013b, 2014). In line with these conceptual and empirical considerations, we assume that SDLO is a positive antecedent of blue-collar workers' IWL.

\section{Hypothesis 3: Self-directed learning orientation is positively related to IWL.}

\section{Organizational Antecedents of IWL}

Time Pressure The Job Demands-Resources model stated that an imbalance between job demands and job resources result in strain at work-but a balance can increase well-being and eagerness to learn (Demerouti et al. 2001). Job demands (e.g., time pressure, high work load) refer to those physical, psychological, social, or organizational aspects of the job that require sustained physical and/or psychological effort or skills; therefore, they are associated with certain physiological and/or psychological costs (cf. Bakker and Demerouti 2007). Many predominantly qualitative studies in various work contexts have found time pressure or lack of time to be important barriers to workplace learning (Crouse et al. 2011; Hicks et al. 2007; Lauber et al. 2010; Lohman 2000; Lohman 2005, 2006; Svensson et al. 2004; White et al. 2000). 
This often concerns blue-collar workers: Especially when the company's order books are full, some machines must run almost non-stop in three-shift operation. The employees are encouraged to work fast and to produce as many units as possible. Then they lack time to learn informally: Time pressure inhibits workers from reflecting on their own work and obtaining feedback on their work performance.

Previous studies have shown that the lack of time has significant negative relationships with the informal learning components interaction with supervisors (van der Heijden et al. 2009; Van der Klink et al. 2014) and learning value of the job (van der Klink et al. 2014). Chan and Auster (2003) stated that barriers to participation which included lack of time significantly, negatively predicted participation in informal learning activities. Based on these considerations, we assume that time pressure is a negative antecedent of blue-collar workers' IWL.

Hypothesis 4: Time pressure is negatively related to IWL.

Social Support: Supervisor Support, Coworker Support, and Error-Related Learning Climate Social support refers to the total amount of helpful interactions at work available from both supervisors and coworkers-it is a core component of the Demand Control Support (DCS) model (Karasek and Theorell 1990). Both sources may provide reinforcement for the use of learning on the job behavior to the employees (Russ-Eft 2002). According to the active learning hypothesis (sometimes also called activation hypothesis) of the DCS model, employees who work in jobs characterized by high job demands, high control, and high social support will show an intensive learning and developing behavior (Karasek and Theorell 1990). Rouiller and Goldstein (1993), regarding the learning transfer context, added the climate within the organization as a third supportive factor. The meta-analysis of Colquitt et al. (2000) on learning motivation has also used this classification. In our study we thus cover social support considering the three subconstructs supervisor and coworker support for learning and learning climate (more specific: error-related learning climate, see below). Because of the overlap in content and the common "social core" of the subconstructs, we regard them as parts of a higher-order factor called social support.

Supervisor Support Blue-collar workers are often involved in highly hierarchically organized work processes and are dependent on the direct instructions of their supervisors. Therefore, supervisors play an important role in supporting IWL: They may allow room for learning, are available for questions and feedback and can give workers the feeling that learning and competency acquisition is desirable. Previous studies in different work contexts have found significant positive relationships between supervisor support and IWL (Birdi et al. 1997; Chan and Auster 2003; Van Doorn et al. 2016; Else Ouweneel et al. 2009; Sanders et al. 2011). Specifically, Choi and Jacobs (2011) established a positive link between supervisor support and the informal learning component learning with others. Regarding low-qualified employees, 
Kyndt et al. (2013b) found that organizational support is a positive predictor of learning intention.

Coworker Support The most important guides and counterparts of blue-collar workers during learning at work are usually their direct colleagues. The worker receives tips and advice from the colleagues, feedback on work performance, and encouragement to try out one' s own solutions for work-related problems. Previous research has shown the connection between coworker support and IWL (e.g., Van Doorn et al. 2016; Else Ouweneel et al. 2009) across different work contexts. According to Van der Klink et al. (2014), team support in terms of learning is positively related to the informal learning categories interaction with supervisors, learning value of the job, and networking within and outside the organization.

Error-Related Learning Climate Errors inevitably occur during the work process. The crucial question is how the organization deals with employees' mistakes: The organization can point out the negative consequences, such as loss of time or faulty products-or emphasize the positive consequences, such as learning and innovation (van Dyck et al. 2005; Frese and Keith 2015). In short, the climate for learning from errors, also known as error-related learning climate, may differ. Error-related learning climate can be defined as "shared perceptions of the members of an organization or organizational unit concerning practices, processes, structures, and behaviors that support or hinder the benefit that organizations can draw from errors." (Putz et al. 2013, p. 519). Managers in particular serve as role models. Harteis et al. (2008) showed, based on a sample with people from high technology and service field companies, that managers rated the beneficial effects of mistakes more positively than working staff members. However, in the production area blue-collar workers often operate in an environment where they only must repeat a few, sometimes very simple, work steps. If errors happen here, a negative reaction by executives could confuse the workers and hinder the learning process (Zhao 2011; Zhao et al. 2018) - because errors typically lead to negative emotions among employees, which are even more intense when the errors are publicly visible (Rausch et al. 2017). A climate of safety could prevent employees from being insecure and afraid of making mistakes, increases the effectiveness of error learning (Putz et al. 2013), and is also regarded as a promoter of workplace learning (Bauer et al. 2016; Nikolova et al. 2014; Rybowiak et al. 1999).

Based on the presented considerations on supervisor support, coworker support and error-related learning climate, we assume that the higher-order construct social support is a positive antecedent of blue-collar workers' IWL.

Hypothesis 5: Social support is positively related to IWL. 


\section{Learning Outcomes of IWL}

Job Involvement Employees' opinions on how important they value their work compared to other factors in life may differ. This is illustrated in their job involvement which is defined as the degree to which a person is identified psychologically with work, or the importance of work to a person's total self-image (Lodahl and Kejner 1965, p. 24). According to the already mentioned active learning hypothesis of the DCS model (Karasek and Theorell 1990), high levels of involvement are expected among those employees who hold active jobs (Taris et al. 2003). Landsbergis et al. (1992) confirmed this empirically, using a sample of male employees from various occupations. According to Taris et al. (2003), job involvement is also one of the most frequently investigated outcome clusters in the context of learning-related research on the DCS model.

This may also be relevant in the field of industrial work: Many blue-collar workers work to earn money and feed their families-not because they love their jobs. Nevertheless, some workers identify very strongly with their workplace and the machines, for whose optimal operation they have acquired a wealth of experience over many years, acknowledging the meaningfulness of their own work (cf. Hackman and Oldham 1980). In line with this, Cerasoli et al. (2018) considered work involvement as an IWL outcome, too.

According to previous research, the motivation to learn within trainings, which could be regarded as similar to the learning intention from the model of Tannenbaum et al. (2010), is moderately positively linked to job involvement (Colquitt et al. 2000; Maurer et al. 2003). Other studies found positive relationships of participation in voluntary employee development activities and career-related continuous learning with job involvement (Hurtz and Williams 2009; Rowold and Schilling 2006). Taking these considerations and findings into account, we assume that job involvement is a positive learning outcome of blue-collar workers' IWL.

\section{Hypothesis 6: IWL is positively related to job involvement.}

Newly Acquired Competency For an effective performance, a worker needs to acquire competency which refer to collections of knowledge, skills, abilities, and other characteristics (KSAOs; Campion et al. 2011). These KSAOs can be acquired through both training and informal learning (Kyndt and Baert 2013). Even though individual learning outcomes vary and always must be considered context-specific, developing competency is a key learning outcome (Crouse et al. 2011). Some previous studies have examined competencies or KSAOs as learning outcomes (e.g, Janssens et al. 2017; Kyndt et al. 2016a; Nikolova et al. 2014a, b; Spreitzer et al. 1997).

Although blue-collar workers often perform simple tasks, they occasionally require extensive competencies to manufacture products that meet the customized requirements which arise, for instance, in often highly specialized SMBs (Decius and Schaper 2017). Through IWL, for instance, by seeking feedback on their own work performance, workers often acquire the KSAOs easily and quickly. As workplace learning research has shown, a deep learning approach (i.e., an intrinsic 
interest in a topic and aim for understanding and development of specific competencies) at work predicts job-specific core skills (i.e., technical knowledge, risk management, customer orientation, and willingness to change) among bank managers (Froehlich 2017; Froehlich et al. 2014). Rowold and Kauffeld (2009) stated that IWL predicts professional, social, and method competency. According to the above considerations and previous research, we assume that newly acquired competency is a positive learning outcome of blue-collar workers' IWL.

\section{Hypothesis 7: IWL is positively related to acquisition of new competency.}

Organizational Citizenship Behavior According to social exchange theory (Blau 1964), a person who has received valuable resources—e.g., learning time, freedom and permission to try things out for themself, or opportunities to exchange experiences-is motivated to give something back to others, e.g., in form of organizational citizenship behavior (OCB; Cropanzano and Mitchell 2005; Eby et al. 2015). OCB refers to "individual behavior that is discretionary, not directly or explicitly recognized by the formal reward system, and in the aggregate promotes the efficient and effective functioning of the organization" (Organ 1988, p. 4). Williams and Anderson (1991) distinguished OCB with respect to the target of the behavior: into OCB toward individuals within the organization (OCBI), and OCB toward the organization as a whole (OCBO). Considering social exchange theory, we focus on the OCBI category. Somech and Drach-Zahavy (2004) found a positive link between learning behavior and OCBI among teachers that was higher than the link to OCBO. Defining OCBI, we refer to Williams and Anderson (1991) who stated that OCBI are behaviors which "immediately benefit specific individuals and indirectly through this means contribute to the organization (e.g., helps others who have been absent, takes a personal interest in other employees)" (p. 602).

In the context of IWL, this is relevant for blue-collar workers in the following way: In order to learn effectively, workers need certain resources provided by the organization. In the case of informal learning, these are, for instance, time to reflect on one's own work performance and identify opportunities for improvement, or permission to try out one's own ideas at work. Colleagues offer opportunities for feedback and exchange of experiences, from which the self-directed learner benefits. The learner therefore wants to give something back to his supervisors and colleagues, as is the case with mentoring, which leads to OCBI (Eby et al. 2015). The learner may share newly acquired knowledge, gives feedback to colleagues (such as he or she had received previously), and prevents them from too much workload. Because both individuals and the organization benefit in this way, OCB is an important outcome and performance criterion in blue-collar work.

Previous studies have found positive relationships between workplace learning and OCB-like constructs such as corporate sense (van der Heijden et al. 2009; Van der Klink et al. 2014) or current performance (Spreitzer et al. 1997; nine performance criteria were collected and summarized). Pierce and Maurer (2009) established a positive relationship between work-related development activities and OCB, using a sample of professionals and executives from a logistics company. Choi et al. 
(2019) considered OCB as a proxy for job performance and measured it with four items from the OCB scale by Williams and Anderson (1991). In their cross-sectional study among South Korean commercial banks and public agencies, IWL was the strongest predictor of job performance/OCB. We also assign OCB to the performance category in the APO Framework, which is described as a learning outcome in the Cerasoli-framework, too. In line with these conceptual and empirical considerations, we assume that OCBI is a positive learning outcome of blue-collar workers' IWL.

Hypothesis 8: IWL is positively related to organizational citizenship behavior $(O C B I)$.

\section{Methods}

\section{Measures}

In the following, we present the questionnaire scales used to operationalize the constructs of the APO framework within the I-P-O model. English scales were translated into German using a translation-backtranslation process. To test the questionnaire for comprehensibility and practicality, we conducted five interviews with blue-collar workers from the target group, using thinking aloud technique (Flaherty 1975; Willis 2005). Based on the interview results, we made changes to six items, as described below for each of the three measures concerned. We used for all items the same sixpoint Likert scale to avoid cognitive overload among participants and to ensure good data quality (Döring and Bortz 2016): 1= Do not agree at all, $2=$ Largely not agree, $3=$ Rather not agree, $4=$ Rather agree, $5=$ Largely agree, $6=$ Fully agree .

Informal Workplace Learning (8 Items, $\boldsymbol{a}=.79$ ) To measure informal learning in the workplace, we used the short scale of Decius et al. (2019). The scale covers each of the eight factors of the IWL octagon model with one item. A sample item (which covers the factor Trying and Applying own ideas) is: "I use my own ideas to improve tasks at work".

Curiosity (5 Items, $\boldsymbol{a}=.77$ ) We measured curiosity with the facet Stretching (i.e., motivation to seek out knowledge and new experiences) from the Curiosity and Exploration Inventory-II (Kashdan et al. 2009). A sample item is: "I view challenging situations as an opportunity to grow and learn."

Learning Goal Orientation ( 5 Items, $\boldsymbol{a}=\mathbf{8 9}$ ) To operationalize the learning goal orientation, we used the scale of the same name by VandeWalle (1997), which originally consisted of six items. With one of the items ("For me, development of my work ability is important enough to take risks.") we already have had doubts about the suitability for blue-collar workers after the thinking aloud interviews, 
as the workers in their working environment are not allowed to take any risks and risk taking is often sanctioned. Because the discriminative power (i.e., the item-total correlation corrected) of this item was also the lowest on the scale with .51 and the internal consistency of the scale without the item increased from $\alpha=.875$ to $\alpha=.887$, this item was removed before further analysis due to those content considerations. A sample item of the final scale version is: "I often look for opportunities to develop new skills and knowledge."

Self-Directed Learning Orientation ( 3 Items, $\boldsymbol{a}=.79$ ) We used a subset of items from the self-directed learning orientation scale and selected those items that covered the self-starting approach aspect of the construct (Gijbels et al. 2010; Raemdonck et al. 2014b). The three items are: "I grab learning opportunities immediately to attain my goals.", "No matter what the odds, if I want to undertake a work-related learning activity I will make it happen.", and "When I want to learn something new for my job, I can always find a way to learn."

Time Pressure ( 3 Items, $\boldsymbol{a}=.74$ ) In order to measure time pressure, we selected two time-related items from the Richter et al. (2000) scale on work intensity and added the item "Often I do not manage my work in the given time." The other two items are: "My company requires me to work very quickly." and "I often have too little time and am under time pressure."

Supervisor Support (4 Items, $\boldsymbol{a}=.90$ ) We used a subscale from the learning culture inventory of Sonntag et al. (2005) covering learn-oriented executive tasks. The results of the thinking-aloud interviews suggested that three of the four items were phrased too complicated for blue-collar workers. Hence, we modified the item formulations; for instance, we changed the item "My manager supports me in taking advantage of personnel development opportunities and finding suitable offers for me." into the simplified form "My foreman or boss helps me to find suitable training courses for me." The other two simplified items are: "My foreman or boss supports me in learning independently" and "My foreman or boss is interested in what I am learning." The other original item was "My supervisor supports us employees in trying out new solutions, even if mistakes are made in the process."

Coworker Support (4 Items, $\boldsymbol{a}=\mathbf{8 7}$ ) We used a subscale from the learning culture inventory of Sonntag et al. (2005) covering learning atmosphere and support from colleagues. The items are: „We employees motivate each other to learn and try out new things.", "My colleagues are interested in things that I have newly learned.", "My colleagues let me share their experiences.", and "We employees give each other feedback on our work performance."

Error-Related Learning Climate (4 Items, $\boldsymbol{a}=\mathbf{8 7}$ ) We measured error-related learning climate using the facet Principles and values from the organizational learning from errors scale (Putz et al. 2013; p. 536, items 13 - 16). A sample item is: "People 
in our organization believe that errors at work can be a helpful part of the learning process."

Job Involvement (4 Items, $\boldsymbol{a}=.75$ ) We used the short version of the scale from Lodahl and Kejner (1965) to measure job involvement. The scale was developed based on samples of nurses, engineers and students. For blue-collar workers, we made two adjustments considering the thinking-aloud interview results. We removed the item "I live, eat, and breathe my job" because this metaphor was not understood by the interviewees and such identification with their own work seemed exaggerated to most blue-collar workers. In addition, we removed the item 'I'm really a perfectionist about my work", as it has turned out that the workers are urged to work without mistakes in their limited area of responsibility, but that they have no way of perfecting their work outcomes beyond that. The scale we used thus contained four items, e.g., "The major satisfaction in my life comes from my job".

Newly Acquired Competency ( 3 Items, $\boldsymbol{a}=.93$ ) We used the sub-scale competency development from the learning outcome measure of Decius et al. (2019). A sample item is: "After I have learned something new for myself, I have a much better understanding of my tasks at work than before."

Organizational Citizenship Behavior (7 Items, $a=.88$ ) To measure organizational citizenship behavior (OCB), we used the subscale OCB toward individuals within the organization (OCBI) by Williams and Anderson (1991). The original scale is formulated from the third person's perspective (he/she) for external assessment. We adapted the formulations for use as a self-assessment scale to the first-person perspective. A sample item is: "I help others who have heavy workloads."

\section{Sample}

We recruited a sample of 709 blue-collar workers in 25 SMBs in Germany, mainly from the industrial sectors of metal processing, plastics processing, tool manufacturing, vehicle construction, mechanical engineering and food industry. The respective production site where the survey took place ranged in size from 10 to 240 employees (the largest company had 900 employees across all sites in different locations, but we only surveyed employees at one of the sites). ${ }^{3}$ The workers filled out a paperpencil questionnaire on a voluntary basis. Depending on the company, the questionnaires were distributed by works council representatives or supervisors. The questionnaires were sent by post from the university either directly to the works council or to the personnel development department for forwarding to the supervisors. The employees returned the questionnaires in a sealed envelope via a trusted representative of the works council or anonymously threw it into a collection box. The content

\footnotetext{
3 As a supplementary analysis, we included company size as a dichotomous factor $(<125$ employees $=$ smaller SMBs; $125-250$ employees $=$ larger SMBs $)$ as a predictor of IWL in our overall model. There was no significant effect, $\beta=-.03, p=.144$.
} 
of the box was either sent back to the university in a package by the works council or the first author of this study picked up the sealed box in person. No incentives to participate in the study were distributed to the workers; however, each company received an individual evaluation report. The response rate was 38\%. As part of the data cleaning we removed two cases from the sample in which the participant had answered all the questions in the questionnaire with 1 in one case and 6 in another. Five times we also found response patterns indicating careless completion of the questionnaire (Meade and Craig 2012) and removed these cases as well. ${ }^{4}$

702 cases remained in the data set. The following percentages refer to those participants who provided valid information on the respective demographic category. $74.8 \%$ were male and $25.2 \%$ female - a typical pattern for the industries involved. For reasons of anonymity, age was surveyed in categories as followed (percentage distribution in brackets): 16-25 years (17.0\%), 26-35 years (19.4\%), 36-45 years $(18.8 \%), 46-55$ years $(30.3 \%)$, 56 years and older (14.4\%). Considering the educational background, $16.3 \%$ did not finish any systematic vocational education, $59.6 \%$ finished a vocational education, $9.5 \%$ got a graduate academic degree, $14.6 \%$ miscellaneous. $43.5 \%$ stated that they worked in their learned occupations, $56.5 \%$ had learned another occupation and were now working outside their field of vocational education. $17.2 \%$ stated that they had been with the company for less than one year, while $25.9 \%$ had worked in the company for more than 20 years. The employees worked in the following production areas: Assembly/machining/processing (36.4\%), packing/shipping (17.2\%), material supply (8.9\%), quality assurance (7.3\%), maintenance $(4.1 \%) .26 .1 \%$ worked in other areas, including production-related areas such as storage logistics.

To test for possible multi-level influences of the persons belonging to the companies, we calculated the intra-class correlation coefficient (ICC), using the statistics software R (version 3.5.1, R Core Team 2019) with the package ICC (Wolak et al. 2012). A value of 0 indicates complete independence of data (Aguinis et al. 2013; Cohen et al. 2003). The ICC values of most scales were low and ranged between .04 and .10 (except for IWL with .11, and supervisor support with .14). Therefore, we assumed that the company affiliation of the workers has no biasing influence, so that it was not necessary to apply a multi-level design in the analysis.

\section{Analyses}

As preliminary analyses, we calculated the correlations between the constructs as well as descriptive values $(M, S D)$. To determine the reliability, we computed Cronbach's Alpha and McDonald's Omega, which is based on more realistic statistical assumptions than Alpha (Dunn et al. 2014), as measures of internal consistency. We used structural equation modeling (SEM) to empirically represent the I-P-O model and to test the hypotheses arising from the APO framework, because SEM is a statistical technique to test a set of relationships representing multiple equations using

\footnotetext{
${ }^{4}$ We also conducted our focal analyses including these cases, but the results did not differ substantially.
} 
a combination of statistical data and qualitative conceptual assumptions (Hair et al. 2010; Kline 2016).

Curiosity, learning goal orientation, self-directed learning orientation, time pressure, and social support acted as predictors of IWL. We modelled social support as a higher-order factor, consisting of the three sub-constructs supervisor support, coworker support, and error-related learning climate, according to the studies of Susomrith and Coetzer (2019) and Nikolova et al. (2014). As a preliminary analysis, we checked the psychometric values of this higher-order factor, using Confirmatory Factor Analysis (CFA). IWL in turn acted as a predictor of job involvement, newly acquired competency, and organizational citizenship behavior as learning outcomes. We examined the path coefficients between the constructs to assess whether there was support for the hypotheses. All these constructs-in case of social support the three sub-constructs at the lower level-were latently modelled with three to seven items.

For modeling the IWL scale, we used the second-order structure of the octagon model of Decius et al. (2019), on which the scale is based. We let the two related items load onto one subfactor (e.g., the items for direct feedback and vicarious feedback onto the subfactor feedback), and then let the four subfactors load onto the IWL factor. This model structure has proven superior to the alternative of loading all eight items onto one IWL factor in a validation study of the IWL short scale (Decius et al. 2021, submitted for publication).

Mitchell and Maxwell (2013) stated that "it is understandable why researchers use cross-sectional studies to test mediation: there are many practical aspects to consider in designing a study. ... However, longitudinal studies are superior to test mediation." (p. 308 f.). Because we had to deal with the limitations of the crosssectional design in the present study, we additionally considered two alternative, separate submodels as a robustness check, following methodological recommendations (e.g., Iacobucci 2010; Weston and Gore 2006): on the one hand only with the antecedents and IWL, on the other hand only with IWL and the learning outcomes.

We performed latent SEM calculations by using $\mathrm{R}$ with the package lavaan (Rosseel 2012). As a pretest, we examined the normal distribution assumption. According to Kline (2016), multivariate normal distribution in many cases can be tested approximately "through inspection of univariate frequency distributions" (p. 74). Because the values for skewness (-1.25 to 0.41$)$ and kurtosis (-1.03 to 2.24) were in a low range, we assumed an approximate normal distribution (cf. Cain et al. 2017; Kline 2016). Thus, we used the Maximum Likelihood (ML) method for estimation instead of an alternative asymptotically distribution free (ADF) estimator (cf. Shin et al. 2009). We applied bootstrapping technique with 1000 draws to get more robust results (Shrout and Bolger 2002). For scaling factors in SEM, we applied the effects coding method (Little et al. 2006) which "constrain[s] the average pattern coefficient across all indicators of the same factor to equal 1.0 in the unstandardized solution" (Kline 2016, p. 200). We imputed missing values (2.3\% in total) using the Full Information Maximum Likelihood (FIML) method which is recommended for SEM by Kline (2016), because FIML "will produce accurate parameter estimates where traditional approaches fail" (p. 87) and maximizes statistical power (Enders 2010). 
The ratio of participants $(N=702)$ to items $(50)$ in the model was $14: 1$, above the recommended minimum of 10:1 (Hair et al. 2010).

To evaluate the model fit we used the model chi-square value and the following global model fit criteria recommended by Kline (2016, p. 269): Comparative Fit Index (CFI), Standardized Root Mean Square (SRMR), Root Mean Square Error of Approximation (RMSEA). According to Weston and Gore (2006), the minimum requirements for a decent model are these values: $\mathrm{CFI} \geq .90$, RMSEA $\leq .10$, and SRMR $\leq .10$; a good fit can be assumed if CFI $\geq .95$, RMSEA $\leq .06$, and SRMR $\leq .08$. If a value lies between these limits, "readers should consider the sample size used to estimate the model (using more stringent criteria for samples larger than $\mathrm{n}=$ 500) and the model complexity (using more stringent criteria for less complex models)" (Weston and Gore 2006, p. 743).

We also applied Harman's single factor test, which at least approximates whether common method variance might be a problem (Podsakoff et al. 2003). If the fit of a model in which all items load on a single factor is worse than the fit of the hypothesized model, common method variance is probably not a problem (cf. Choi and Jacobs 2011). In addition to this rough, rather unspecific test, we examined two alternative nested models, each containing only the five antecedents: In model A we allowed the latent constructs to covariate; in model B we included a higherorder factor. If model B had a better model fit than model A, this would contradict our assumption that the constructs are distinct. In addition to the model fit criteria already mentioned, we used the Akaike Information Criterion (AIC), with which nested models can be compared (the smaller the AIC, the better the model; Kline 2016).

As a supplementary analysis, we included task complexity as a dichotomous factor (lower complexity vs. higher complexity) as predictor of IWL in our overall model-multi-group comparisons would not have been validly feasible due to the model's structural intricacy and the small sample size in the subgroups. Activities with lower complexity consist, for instance, of simple assembly tasks that can be mastered even by semi-skilled and unskilled workers after a few days of instruction. Activities of higher complexity comprise elaborate production processes that require many years of experience and expertise (e.g., supportive tasks in machine construction). Of the 25 companies, eleven companies could be assigned to such a more complex activity, resulting in $N=327$ participants. The group of lower complexity includes 14 companies with $N=375$ participants.

\section{Results}

\section{Preliminary Descriptive Analyses and Model Fit Analyses}

Table 2 shows the manifest correlations as well as the descriptive statistic of the constructs examined. The relations of variable means are in the medium to large range and provide a strong basis for SEM. Because the three personal antecedents curiosity (CU), learning goal orientation (LGO) and self-directed learning 


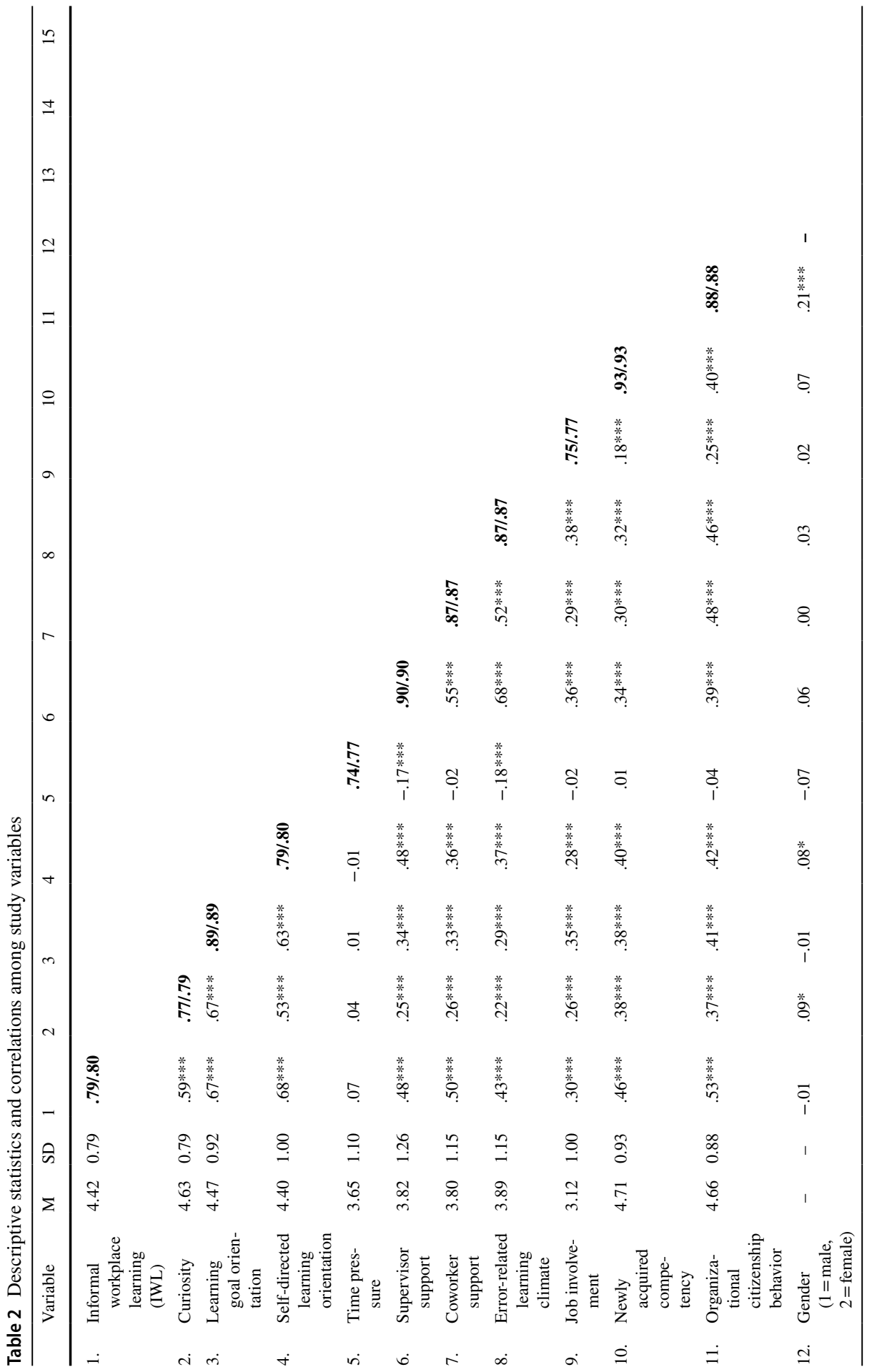




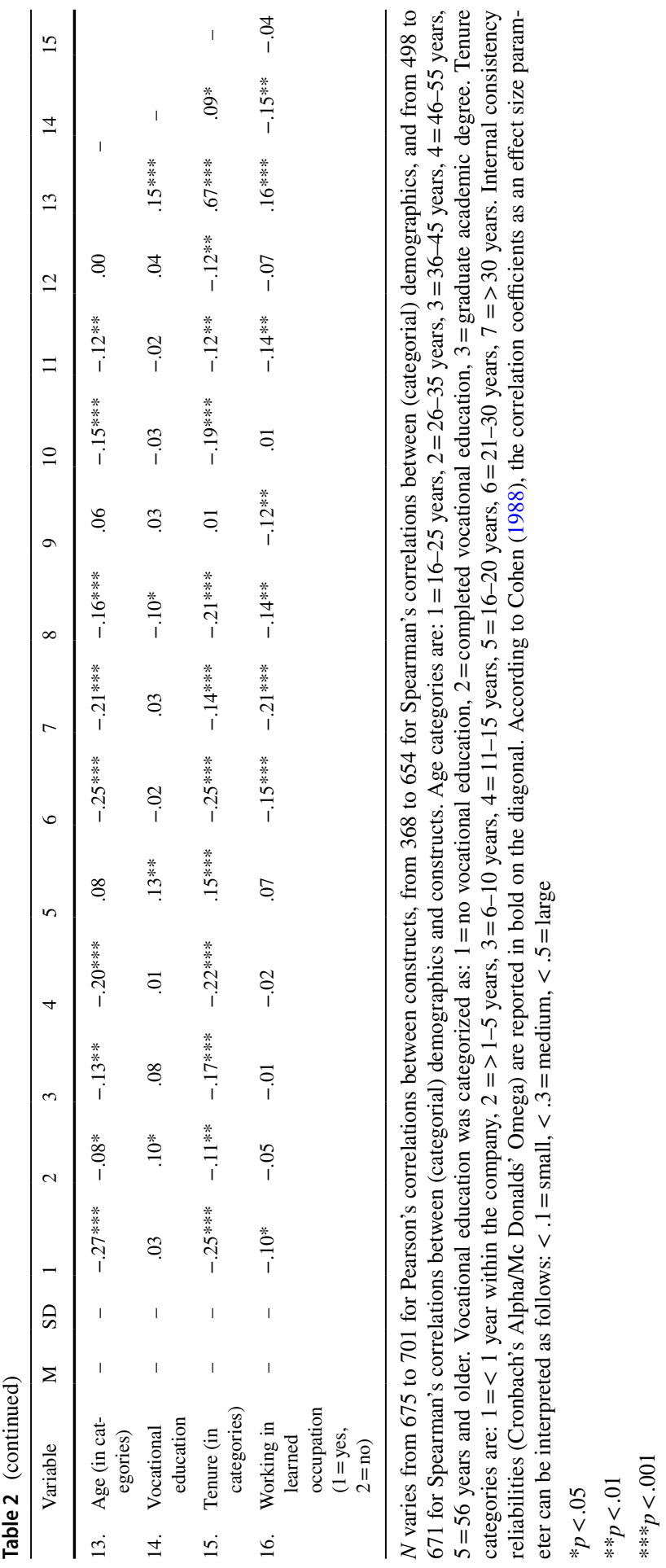


orientation (SDLO) are highly correlated, we additionally tested the discriminant validity of these constructs. Based on the latent factor loads, we calculated the average variance extracted (AVE) value for each construct and the shared variance (SV; i.e., the squared latent correlation) between the constructs. If the AVE values of the two constructs included in each calculation are greater than the SV values between these constructs, discriminant validity can be assumed (Farrell 2010). The AVE values of LGO (.618) and SDLO (.571) were higher than the SV between LGO and SDLO (.551). The AVE values of CU (.432) and SDLO (.571) were approximately equal or higher than the SV between CU and SDLO (.436). The AVE values of CU (.432) and LGO (.618) were lower or higher than the SV between CU and LGO (.604). Despite this deviation in CU, the overall trend suggested discriminant validity between the constructs.

Cronbach's Alpha ranged between $\alpha=.74$ and $\alpha=.93$, McDonald's Omega ranged between $\omega=.77$ and $\omega=.93$ (see Table 2). Not all constructs can be assumed to have a good reliability-however, the majority of the scales fulfilled the minimum criterion that the reliability value should not be below .80 (Carmines and Zeller 1979). The structural equation model showed an acceptable overall fit, $\chi^{2}(1147)=3142.504, p<.001 ; \mathrm{CFI}=.90 ; \mathrm{SRMR}=.06 ; \mathrm{RMSEA}=.05,90 \%$ $\mathrm{CI}=[.048, .052]$. Especially the values of the SRMR and the RMSEA indicated a good fit. Although the CFI was only in an acceptable range, the high model complexity with 1147 degrees of freedom had to be considered here, thus we judged the CFI in this case not as optimal, but sufficient (cf. Weston and Gore 2006). The standardized loads of the items on the respective latent constructs ranged between .35 within the job involvement construct-which is together with .47 (within curiosity) the only load below .5-and .97 within time pressure.

Harman's single factor test resulted in a model fit, $\chi^{2}(1175)=10,847.298$, $p<.001 ; \mathrm{CFI}=.49 ; \mathrm{SRMR}=.10 ; \mathrm{RMSEA}=.11,90 \% \mathrm{CI}=[.106, .110]$, which is substantially worse than in the hypothetical model. The Akaike Information Criterion (AIC) also had a significantly higher and thus worse value in the single factor model with $\mathrm{AIC}=101,550.627$ than the hypothesized model with $\mathrm{AIC}=93,901.833$. In the model comparison, model A with the covarying constructs, $\chi^{2}(337)=1028.417, p<.001 ; \mathrm{CFI}=.94 ; \mathrm{SRMR}=.04 ; \mathrm{RMSEA}=.05,90 \%$ $\mathrm{CI}=[.050, .058]$; $\mathrm{AIC}=53,231.768$, showed a better model fit in all criteria than model B with the higher-order factor, $\chi^{2}(342)=1103.637, p<.001 ; \mathrm{CFI}=.93$; $\mathrm{SRMR}=.06 ; \mathrm{RMSEA}=.06,90 \% \mathrm{CI}=[.053, .060] ; \mathrm{AIC}=53,296.988$. Even though we cannot completely rule out a common method bias, there was no indication of a high common method variance.

The CFA to examine the higher-order factor social support-consisting of the three sub-constructs supervisor support, coworker support, and error-related learning climate-resulted in a satisfactory model fit, $\chi^{2}(51)=171.536, p<.001$; $\mathrm{CFI}=.98 ; \mathrm{SRMR}=.03$; $\mathrm{RMSEA}=.06,90 \% \mathrm{CI}=[.049, .068]$. Thus, we consider our theoretical assumption of modelling the three constructs together as confirmed. 
Table 3 Estimator and model fit comparison of two submodels and the full model of antecedents, informal workplace learning, and learning outcomes

\begin{tabular}{llll}
\hline & Antecedents $\rightarrow$ IWL $\quad$ IWL $\rightarrow$ outcomes & $\begin{array}{l}\text { Antecedents } \rightarrow \\
\text { IWL } \rightarrow \text { outcomes (full } \\
\text { model) }\end{array}$ \\
\hline Estimator & & & \\
$\quad$ Curiosity & $.25(.24)$ & $.28(.27)$ \\
$\quad$ Learning goal orientation & $.28(.21)$ & $.24(.19)$ \\
Self-directed learning orientation & $.41(.31)$ & & $.33(.25)$ \\
Time pressure & $.10(.07)$ & & $.09(.07)$ \\
Social support & $.16(.12)$ & $.35(.44)$ & $.44(.57)$ \\
Job involvement & & $.54(.72)$ & $.55(.73)$ \\
Newly acquired competency & & $.61(.75)$ & $.62(.77)$ \\
Organizational citizenship & & & \\
$\quad$ behavior & & & $3142.50 / 1147$ \\
Model fit & & $629.87 / 199$ & .90 \\
$\chi^{2} / d f$ & $1859.55 / 572$ & .94 & .05 \\
CFI & .90 & .06 & .06 \\
$\quad$ RMSEA & .06 & .05 & \\
$\quad$ SRMR & .06 & & \\
\hline
\end{tabular}

$I W L$ informal workplace learning, CFI comparative fit index, RMSEA root mean square error of approximation, $S R M R$ standardized root mean square. Values shown are standardized parameter estimates, nonstandardized values are in brackets. All $p$ values of the estimators are below .001, except for learning goal orientation $(p=.002)$ and time pressure $(p=.004)$

Overall, the preliminary analyses confirm that the model established can be evaluated properly based on the existing data. In the following, we hence present the results of the structural equation model analysis and test the hypotheses established in this study.

\section{Structural Equation Model Assessment and Hypotheses Testing}

Table 3 shows the parameter estimates and the model fit values of the two submodels and the full model. To increase the transparency of the results and to improve interpretability, Grace and Bollen (2005) recommended providing the non-standardized path coefficients for SEM, too. In the first submodel we included the antecedents and IWL, in the second submodel IWL and the learning outcomes, and in the full model the antecedents, ${ }^{5}$ IWL and the learning outcomes. All estimators were significant in all models. The estimators were similar in all three models, except for social support, which had a much larger size in the full model. Selfdirected learning orientation also had a smaller estimator in the full model but was

\footnotetext{
5 As a robustness test, we ran supplemental analysis of the full model once without the organizational antecedents and once without the personal antecedents. The coefficients of the remaining paths and model fit values were similar in all models.
} 


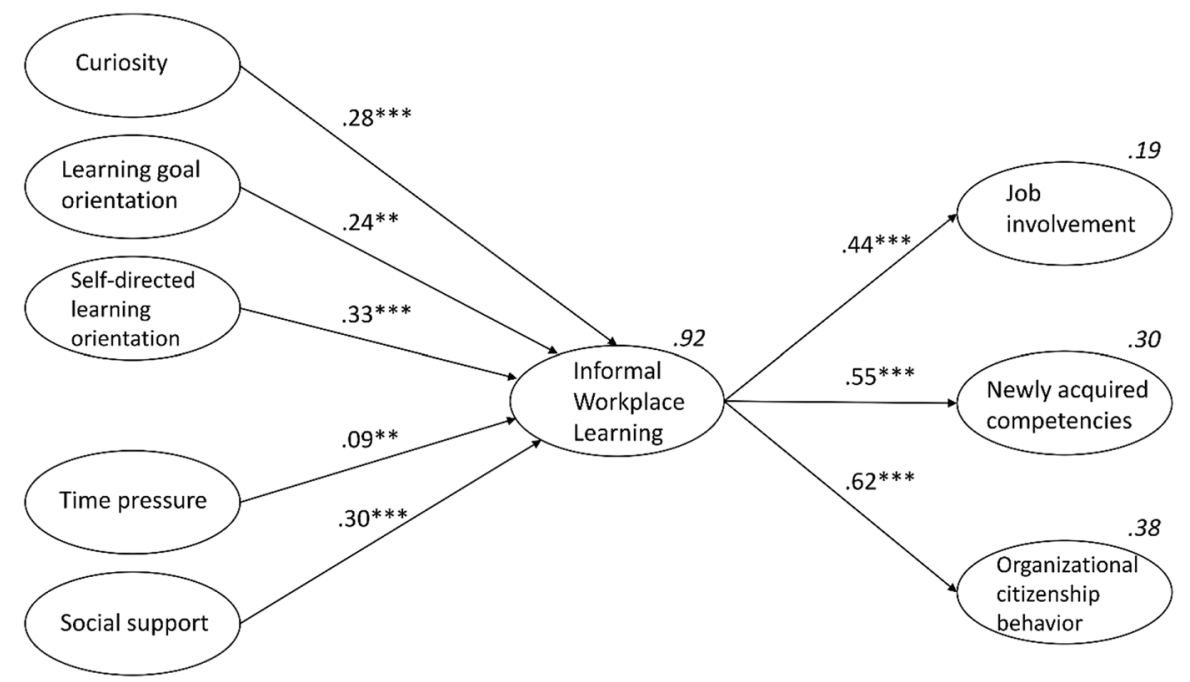

Fig. 1 Standardized path coefficients of the structural equation model (SEM). Note. The manifest indicators and residuals were omitted for simplified presentation. Social support is a second-order construct, which consists of the following three sub-constructs (in brackets the respective factor load): supervisor support (.88), coworker support (.71), and error-related learning climate (.85). The explained variance $\left(R^{2}\right)$ is given for informal workplace learning and for the endogenous latent variables (learning outcomes). ${ }^{* *} p<.01, * * * p<.001$

still the antecedent with the largest size. Job involvement had a larger estimator in the full model but was still the learning outcome with the smallest size.

To test the hypotheses, we used the results of the full model (cf. Figure 1 for an overview of the factor structure). Regarding personal antecedents, curiosity, learning goal orientation, and self-directed learning orientation indeed had positive significant path coefficients, which supported hypotheses 1,2 , and 3. Regarding organizational antecedents, social support showed a significant positive association with IWL, so that hypothesis 5 was supported. Interestingly, we did not find the expected negative relationship between time pressure and IWL, but a significant positive association, even if this is only weak. Hypothesis 4 was thus not supported. Regarding learning outcomes, IWL had a positive significant relation to job involvement, newly acquired competency, and organizational citizenship behavior; these results have provided support for hypotheses 6, 7, and 8. In our supplementary analysis of task complexity, we found a small positive effect of task complexity as a predictor of IWL, $\beta=.12, p<.001$. This means that blue-collar workers who perform more complex tasks learn slightly more informally.

\section{Discussion}

In this study we developed the APO framework to describe the antecedents and outcomes of IWL among blue-collar workers. We then empirically tested the model resulting from the APO framework. We have been able to find empirical support 
for seven of the eight previously derived hypotheses. Thus, we can contribute to answering the research questions raised at the beginning — at least to a certain extent and considering a few limitations we will discuss afterwards.

The first research question has been: Which of the personal constructs curiosity, learning goal orientation, and self-directed learning orientation and which of the organizational constructs social support and time pressure are relevant antecedents of informal learning? According to our findings, all the constructs mentioned above are relevant antecedents of IWL, except for time pressure. Self directed learning orientation revealed the strongest relationship with IWL in the structural model, followed by social support, curiosity, and learning goal orientation. These constructs are not only important for IWL among blue-collar workers, but they are also most likely more or less important for other groups of employees (cf. the more general Cerasoli-framework, which provides the conceptual framework for our selection of constructs). However, an important contribution of our study is to have shown that these constructs are also important antecedents of IWL for blue-collar workers, and which of these constructs indicate particularly high associations with IWL in the context of blue-collar work. We suggest that especially in working environments that are not typical for extensive learning activities, such as production and other blue-collar jobs, the mixture of personal learning dispositions and social support is particularly important. In other professions, such as white-collar jobs, many learning needs arise from work situations with new stimuli (e.g., when dealing with customers and on business trips), so IWL also occurs independently of any specific learning motivation. Blue-collar workers who do routine work either learn little in their everyday work, or they learn when they are driven by a high degree of curiosity, motivation and goal setting. Moreover, many white-collar workers experience social support in learning situations rather indirectly or at sporadic intervals-imagine an employee who teaches herself a new calculation method in Excel by experimenting and using Internet sources. Blue-collar workers, on the other hand, are almost exclusively involved in social environments and 'situated learning' contexts at work (cf. Lave and Wenger 1991) — almost no worker has a private office and experiences ongoing social support and control from colleagues and superiors. Thus, it is not surprising that social support for IWL is very important especially for this target group.

However, we could not find support for the hypothesis that time pressure is related negatively with IWL. In fact, we have found a slightly positive correlation. One reason could be that time pressure implies a high action and problem-solving urge for the employees and may promote learning. Indeed, Kronstad and Eide (2015) found in their interview study with online journalists that time pressure can probably trigger learning. Weststar (2009) showed that job demands are positively associated with formal, informal and non-taught learning. In addition, an individual may perceive a stressor such as time pressure as either a challenge or a hindrance (Cavanaugh et al. 2000). The appraisal is crucial for the consequences that follow: LePine et al. (2004) showed that stress associated with challenges in the learning environment is positively related to learning performance-stress associated with hindrances in the learning environment is negatively related to learning performance. Van Ruysseveldt and Van Dijke (2011) stated that the relationship between 
workload and workplace learning opportunities is an inverted U-curve, with a positive association at low levels of workload and a negative association at high levels of workload. The participants in the present study may have perceived time pressure at work as a challenge, or time pressure may have been too low to have a negative effect on IWL. Future studies could compare challenge and hindrance aspects of job demands in the IWL context. Furthermore, it is noticeable that time pressure hardly correlates with all constructs examined - not just with IWL: Only the slight negative correlations of time pressure with supervisor support and error-related learning climate appeared to be significant (see Table 2). Even if these (non)correlations can be explained theoretically well, it is possible that in complex structural equation models there might be a statistical distortion if all predictors correlate with each other at least moderately, but one does not (cf. Kline 2016). Overall, the positive relationship between time pressure and IWL found in our study should not be overinterpreted because of the low effect size.

A view on the manifest correlations (see Table 2) reveals that age is significantly negatively related to IWL. However, an examination using SEM showed that the path coefficient of age-included in the overall model as an additional predictor for IWL-is not significant. This could be due to the fact that age is also negatively related to all other predictors except time pressure. The supposed age effect could thus be caused by a lower motivation to learn (i.e., learning goal orientation, selfdirected learning orientation) and lower social support.

Our supplementary analysis of task complexity revealed that blue-collar workers who perform more complex tasks slightly learn more informally than those workers who complete less complex tasks. This is consistent with findings from studies such as by Jeon and Kim (2012), who quantitatively examined work characteristics and IWL in various South Korean companies, and by Schürmann and Beausaert (2016), who interviewed employees from a German machinery manufacturer. Although the learning potential of task complexity was discussed conceptually at an early stage (e.g., Ellström 2001), empirical evidence in this context is still scarce. Future studies could address this issue in more detail.

The second research question has been: How is the relevance of the three mentioned personal constructs as antecedents of informal learning compared to the relevance of the two mentioned organizational constructs? Based on the results, we cannot draw a clear conclusion on this: Apart from time pressure, all antecedents have showed similarly high relationships with IWL (between $\beta=.24$ and .33 ). In formal education the learning environment plays a major role. The Aptitude Treatment Interaction approach (Cronbach and Snow 1977) from pedagogical psychology assumed that the teaching method must be optimally adapted to the learner's abilities. The Work Design Growth Model (Parker 2017) also claimed that environmental factors are important for enhancing learning and development. However, in the case of IWL, there is probably no predominance of the organizational environment. The learner's individual characteristics seem to be very important because the learning context is more flexible and less determined in informal learning than in formal learning. Support for this assumption has been provided by the results of Choi and Jacobs (2011), in whose study the personal characteristics showed a high significant relationship with IWL, but the determinants of work environment did not. Thus, it 
may be possible that workers who are personally interested in learning follow their learning needs regardless of the work and learning environment, while less interested workers are hardly motivated to learn by external conditions. The personal factors may have a more proximal effect, while the organizational factors may have a more distal effect. Future research could investigate this assumption.

The third research question has been: Which of the constructs job involvement, newly acquired competence, and organizational citizenship behavior are relevant as learning outcomes of informal learning? The results of our study have indicated that the most relevant learning outcome of IWL seems to be organizational citizenship behavior (performance domain, according to Cerasoli et al. 2018), followed by newly acquired competency (knowledge/skill acquisition domain) and job involvement (attitudes domain). The results are in line with the findings from Cerasoli et al. (2018), where overall performance had the highest relationship (corrected population correlation, $\rho=.42$ ) with IWL, followed by overall knowledge/skill acquisition $(\rho=.41)$, and overall attitudes $(\rho=.29)$.

As with the antecedents, we assume that the three learning outcomes also apply to other groups of employees in different weightings-our study was able to show that these constructs also appear as results of blue-collar workers' IWL. It may seem surprising that a learning outcome such as the behavioral construct OCB, which at first glance appears to be more distal, has a stronger relationship to IWL than the proximal learning outcome newly acquired competence. ${ }^{6}$ In IWL in white-collar jobs (think again of the example of teaching oneself a calculation method in Excel) or formal training (courses with pre-defined learning goals) it should indeed be the case that the newly acquired competence is the main learning outcome. In IWL in blue-collar jobs, however, the learning process is deeply interwoven with work execution and the social environment - as a consequence of this situatedness, pro-social behavior is the most crucial learning outcome: If an employee has learned something through direct feedback, exchange of experiences or an opportunity for experimentation or reflection granted to her in a closely timed work schedule, she probably wants to give something back to her colleagues or superiors. This mechanism can be explained by social exchange theory (Blau 1964; Cropanzano and Mitchell 2005) and is expressed in increasingly shown OCB. Although the acquired competence and job involvement are also important learning outcomes, the behavioral component predominates in the case of blue-collar workers' IWL.

Following the input-process-output perspective, we argue that the variables we have named antecedents precede IWL, and that the variables named learning outcomes follow IWL. However, because our research design did not allow us to investigate causality, these are only conceptual assumptions which we have attempted to illustrate in detail in the theory section above. Nevertheless, one could argue that OCB and job involvement are rather antecedents of IWL than outcomes or at least show reciprocal relationships. Most studies have considered these variables to be outcomes (e.g., Choi et al. 2019; cf. Cerasoli et al. 2018, for an overview). In the context of mentoring, Eby et al. (2015) found in a cross-lagged design an influence from mentoring received from supervisors on employee OCB, but not vice versa.

\footnotetext{
${ }^{6}$ We would like to thank an anonymous reviewer for this indication.
} 
Job involvement can also be seen as a mediator between personal or job characteristics on the one hand and work behaviors such as effort and performance on the other (Brown 1996). Employees who are strongly engaged in IWL could be more liked by their supervisors and thus receive more social support, but this is unlikely to be the case for peers. Employees who spend a large part of their working time on IWL may fall behind with their actual work, which could lead to increased perceived time pressure. However, since IWL, compared to other learning forms, is highly interwoven with the direct execution of the work activity and is triggered by problems in the work process (Marsick and Volpe 1999; Segers et al. 2018), this is rather unlikely. It could be that employees who are strongly engaged in IWL burden themselves with more work as a result of their competence development. However, it is uncertain whether this will lead to a possible feeling of being overwhelmed and under time pressure. In general, more longitudinal research is needed to clarify these relationships.

\section{Limitations, Future Directions and Implications}

\section{Limitations and Further Research Implications}

Using the SEM method, we have implemented a robust analysis procedure for simultaneous consideration of relationships between variables (Kline 2016). However, our study had a cross-sectional design; we thus could not examine effects but only correlations. We can say that the covariance patterns found between the variables are consistent with the assumed structural model, but there may be other structural models to which this applies (cf. Stone-Romero and Rosopa 2008). Only the use of at least three measurement points in a longitudinal design could provide further empirical evidence of causality (Cole and Maxwell 2003; Maxwell and Cole 2007), even if - strictly speaking - this does not yet guarantee the exclusion of confounding variables necessary for causality, which is difficult to establish in field studies such as in this one. Disabato (2016) and Spector (2019), though, argued for the justification of cross-sectional field studies, which can provide valuable impulses on which future longitudinal studies can build. More robust (longitudinal) research designs could also help to better answer the question of antecedents' relative importance, as unique covariance is only a moderate proxy for relative importance. Thus, future research should aim at longitudinal or (quasi-)experimental designs, even if three or more measurement points are difficult to attain in the target group of blue-collar workers without external incentives. One should keep in mind that the use of incentives for participants could possibly lead to lower data quality (Gabriel et al. 2018).

Regarding the model fit, it is evident that the values for RMSEA and SRMR were in a good range, but the CFI value was only in an acceptable range. However, our model is very complex and contains 12 latent constructs estimated from 50 manifest indicators. This complexity should be considered when assessing the model fit (Weston and Gore 2006). The SRMR in particular proved to be a robust measure which is "more sensitive to model misspecification than to sample size or violations 
of distributional assumptions" (Iacobucci 2010, p. 96). In addition, the different fit indices should be interpreted together, as each has its own strengths and weaknesses (Kline 2016), and the rules of thumb for the model fit should not be interpreted overcritically (Iacobucci 2010; Marsh et al. 2004).

The three constructs of personal antecedents have showed high manifest correlations with each other $(.53, .63, .67$; cf. Table 2$)$. This raises the question of potential multicollinearity. However, these high correlations are conceptually justifiable because curiosity, learning goal orientation, and self-directed learning orientation are concepts that are strongly based on the learner's own initiative and responsibility and have a common conceptual core. Yet, the constructs are-as explained in the theory section above-theoretically distinct, internally consistent (Cronbach's Alpha is .77, .79, .89; cf. Table 2) and, for the most part, empirically distinguishable regarding the calculations of discriminant validity.

Nevertheless, we collected all data using self-reports in a single questionnaire. Although the Harman's single factor test and the antecedents' model comparison with and without higher-order factor have showed that common method variance is not a major problem, this cannot be ruled out with certainty. In an ideal scenario, researchers in future studies could reduce the probability of common method biases a priori by choosing a multimethod approach and by using several measurement points (Podsakoff et al. 2003). Further research could include objective performance indicators as outcomes, e.g., production quantities or customer reclamations, or at least performance ratings by others (e.g., supervisors, co-workers).

We also used adaptations of established scales in the questionnaire, which we had modified for the target group of blue-collar workers. Such a procedure is common in psychological and social research, but not without problems regarding validity (Heggestad et al. 2019). To ensure transparency we described the modifications in detail in the measures section. Due to the difficulty of recruiting blue-collar workers for written surveys, we decided against a broad quantitative pretest of the scales. However, before using the modified questionnaire, we piloted the items with interviews among blue-collar workers using thinking aloud technique.

As we mentioned at the beginning, the meta-analysis of Cerasoli et al. (2018) is based on initial studies of varying quality, in which IWL was operationalized in very different ways. This represents a flaw of the otherwise conceptually and theoretically well done and important review study by Cerasoli et al. Since we primarily rely on the Cerasoli-framework for the development of the APO framework, this general critique indirectly applies to our study, too. Developing the APO framework, it also seemed appropriate not to consider all the constructs mentioned as examples in Cerasoli et al.'s study. For the sake of parsimony and complexity reduction of the model, our aim was to cover every domain at specificity level 3 with only one construct, if possible. Nevertheless, we first considered all the constructs mentioned in the Cerasoli-framework, and then decided based on conceptual considerations and empirical evidence which of the constructs might have the greatest relevance for IWL in blue-collar workers. We have provided arguments for our selection of constructs in the theory section, but without claiming completeness. However, the selection can be discussed controversially. An example would be the variable autonomy/job control, which plays a minor role in the work of blue-collar workers (Huang 
2011); in some production contexts, though, employees also work in self-directed teams within production lines.

IWL represents the process component in the IPO model. In the octagon model, six of the eight components cover the learning behavior (all except the two intention components). In this way, we tried to operationalize the learning process in the best possible way. However, in cross-sectional study designs the operationalization of a process is only approximately possible. Future studies could, for instance, use a longitudinal diary design to capture the learning process more robustly and more closely to reality.

\section{Future Conceptual Directions}

Future studies on IWL of blue-collar workers can build on the APO framework and examine IWL over time, for example, how organizational change may affect the entire I-P-O sequence. In the present study, we have used a short scale to measure IWL that covers the entire scope of informal learning. However, the various antecedents may be differently related to the diverse components of IWL, and the components may be differently related to the learning outcomes. Thus, researchers could use the extended eight component IWL scale, which reflects the octagon model of IWL in a more differentiated way (Decius et al. 2019).

The best predictor for IWL, self-directed learning orientation, was considered in our study to be a trait-like variable. Nevertheless, further studies could examine whether this orientation can be enhanced over time, for example, by special forms of training - sensitizing employees to recognize and grasp learning opportunities directly, while also overcoming obstacles to learning. Previous research has shown that self-regulation among unemployed job seekers can be improved by training in learning goal orientation (Noordzij et al. 2013); perhaps improvement is also possible in the context of self-directed learning orientation.

It would be desirable if future research analyzes the learning of blue-collar workers in more depth to determine whether a separate learning theory is needed for this target group. One starting point could be why many blue-collar workers want to learn only those skills and knowledge sets that will enable them to work almost trouble-free-while others, few workers, may want to learn more intensively beyond this "default line", even though this may not result in direct monetary benefits or promotion opportunities. But comparative studies between different groups of workers are also scarce. In the introduction we have presented our assumption that the constructs relevant for IWL are basically similar in different target groups, but with varying weighting and prioritization of the factors. Because of the lack of empirical evidence, future research should specifically compare blue-collar workers and white-collar workers regarding the learning conditions for IWL-such as in stress research, where no differences between the two groups of workers could be found concerning burnout mechanisms (Toppinen-Tanner et al. 2002).

Furthermore, future studies could consider the size of company site or the size of business units (where learning actually takes place) as moderator variables. Researchers should ensure that they receive enough employee data per unit in the 
sample to meet the requirements for the calculation of multi-level analyses, in contrast to the present study. Indeed, working conditions in smaller and larger production companies differ only slightly, because even in larger production halls employees work and learn informally mainly in segregated areas and smaller groups. However, there are hints from interview case studies that the type and extent of IWL and knowledge management may be influenced by company size (Coetzer et al. 2017; Wong and Aspinwall 2004).

\section{Practical Implications}

Managers would like to know how they can promote IWL among their blue-collar workers. Because IWL cannot be regulated directly because of the high autonomy of learners, managers can only design learning environment conditions (Cerasoli et al. 2018; Ellström 2011; Skule 2004). The factor most directly influenced by managers is social support. Managers can try to provide resources and opportunities for blue-collar workers to exchange experiences and support each other, and to facilitate and exemplify a positive error culture in which failures are seen primarily as learning opportunities. Enterprises may also offer informal support to their managers and encourage them to recognize, model and promote the informal learning behavior of their employees (Cerasoli et al. 2018). Although we have found a weak positive connection between time pressure and IWL, we advise against increasing time pressure, as the workers might learn slightly more informally, but other negative effects, e.g., on job satisfaction, could occur.

Based on the results of personal antecedents, another leverage could be the managers' attention to hiring interested, curious, and learning-motivated employees during the selection process-assuming this luxury is possible in times of skills shortages, especially in rural areas. Enterprises may have to adapt their recruitment strategies. If managers also want to send their workers to formal training courses to supplement IWL, it would be worth considering investing not only in professional and technical content but also in communication and cooperation courses as well as goal setting training. This might have a positive effect on social support behavior and learning goal orientation as relevant IWL antecedents. Through coaching or formal training, employees' general informal learning skills could be improved (Cerasoli et al. 2018). Richter et al. (2020) found a spillover effect from formal to informal learning in a longitudinal study: If employees assess formal training as satisfactory when they reflect on it, they use more informal learning strategies afterwards.

Regarding learning outcomes, managers can expect that an increase in IWL will probably lead to positive behavioral effects (organizational citizenship behavior) as well as to an increased acquisition of competency among employees and higher job involvement. Although much of the learning in the workplace takes place informally, the expenses spent by enterprises to promote IWL have so far been rather modest (Berg and Chyung 2008). The findings presented on the outcomes of IWL give the organizations more certainty that investing in learning conditions to support IWL pays off for them and their workers. 


\section{Conclusion}

Our study on antecedents and learning outcomes of informal learning at the workplace has responded to the claim of Cerasoli et al. (2018) and Jeong et al. (2018a) for a clear, differentiated and target group-specific set of IWL's framework conditions and consequences. With the development of the APO framework for bluecollar workers we have presented a basis for future research, having identified important personal and organizational antecedents of IWL. Following the I-P-O model, we also have integrated learning outcomes-which are particularly relevant for practitioners-into the APO framework. In contrast to earlier studies, we have operationalized IWL based on a theoretically sound IWL model (cf. Decius et al. 2019). Using a cross-sectional structural equation approach, we have established the basis for the correlational part of the observational-correlational-experimental loop (Rosenshine and Furst 1973), on which future longitudinal and theory-developing studies can build.

Acknowledgments We would like to thank Melissa Sonntag for her support in literature research and data collection.

Funding Open Access funding enabled and organized by Projekt DEAL.

\section{Declarations}

Conflict of Interest We have no known conflict of interest to disclose.

Open Access This article is licensed under a Creative Commons Attribution 4.0 International License, which permits use, sharing, adaptation, distribution and reproduction in any medium or format, as long as you give appropriate credit to the original author(s) and the source, provide a link to the Creative Commons licence, and indicate if changes were made. The images or other third party material in this article are included in the article's Creative Commons licence, unless indicated otherwise in a credit line to the material. If material is not included in the article's Creative Commons licence and your intended use is not permitted by statutory regulation or exceeds the permitted use, you will need to obtain permission directly from the copyright holder. To view a copy of this licence, visit http://creativecommons.org/licen ses/by/4.0/.

\section{References}

Abel, J., \& Wagner, P. S. (2017). Industrie 4.0: Mitarbeiterqualifizierung in KMU [Industry 4.0: Employee qualification in SMBs]. wt-Werkstattstechnik Online, 107, 134-140.

Abel, J., Decius, J., Güth, S., \& Schaper, N. (2016). Kompetenzentwicklung bei un- und Angelernten in nicht-forschungsintensiven KMU-Status quo und Zukunft einer strategischen Notwendigkeit [competence development for unskilled and semi-skilled workers in non-research-intensive SMBs-Status quo and future of a strategic necessity]. Betriebspraxis \& Arbeitsforschung, 228, 41-50.

Aguinis, H., Gottfredson, R. K., \& Culpepper, S. A. (2013). Best-practice recommendations for estimating cross-level interaction effects using multilevel modeling. Journal of Management, 39(6), 14901528. https://doi.org/10.1177/0149206313478188. 
Baert, H. (2018). Informal learning at work. What do we know more and understand better? In G. Messmann, M. Segers, \& F. Dochy (Eds.), Informal learning at work: Triggers, antecedents, and consequences (pp. 153-187). Oxon: Routledge. https://doi.org/10.4324/9781315441962-8.

Bakker, A. B., \& Demerouti, E. (2007). The job demands-resources model: State of the art. Journal of Managerial Psychology, 22(3), 309-328. https://doi.org/10.1108/02683940710733115.

Bauer, J., Leicher, V., \& Mulder, R. H. (2016). On nurses' learning from errors at work. In S. Billet, D. Dymock, \& S. Choy (Eds.), Supporting learning across working life (pp. 129-145). Cham: Springer. https://doi.org/10.1007/978-3-319-29019-5_7.

Berg, S. A., \& Chyung, S. Y. (2008). Factors that influence informal learning in the workplace. Journal of Workplace Learning, 20(4), 229-244. https://doi.org/10.1108/13665620810871097.

Bernadette Van Rijn, M., Yang, H., \& Sanders, K. (2013). Understanding employees' informal workplace learning: The joint influence of career motivation and self-construal. Career Development International, 18(6), 610-628. https://doi.org/10.1108/CDI-12-2012-0124.

Billett, S. (1995). Workplace learning: Its potential and limitations. Education+ Training, 37(5), $20-27$. https://doi.org/10.1108/00400919510089103.

Bimrose, J., Mulvey, R., \& Brown, A. (2016). Low qualified and low skilled: The need for context sensitive careers support. British Journal of Guidance \& Counselling, 44(2), 145-157. https://doi. org/10.1080/03069885.2016.1145190.

Birdi, K., Allan, C., \& Warr, P. (1997). Correlates and perceived outcomes of 4 types of employee development activity. Journal of Applied Psychology, 82(6), 845-857. https://doi. org/10.1037/0021-9010.82.6.845.

Blau, P. M. (1964). Exchange and power in social life. New York: Wiley.

Blings, J. (2008). Informelles Lernen: Bedeutung, Potenzial und Grenzen in der Kreislauf- und Abfallwirtschaft [informal learning: Significance, potential and limits in the recycling and waste management sector]. Bielefeld: Bertelsmann.

Brett, J. F., \& VandeWalle, D. (1999). Goal orientation and goal content as predictors of performance in a training program. Journal of Applied Psychology, 84(6), 863-873. https://doi. org/10.1037/0021-9010.84.6.863.

Brown, S. P. (1996). A meta-analysis and review of organizational research on job involvement. Psychological Bulletin, 120(2), 235-255. https://doi.org/10.1037/0033-2909.120.2.235.

Bushnell, D. S. (1990). Input, process, output: A model for evaluating training. Training \& Development Journal, 44(3), 41-44.

Button, S. B., Mathieu, J. E., \& Zajac, D. M. (1996). Goal orientation in organizational research: A conceptual and empirical foundation. Organizational Behavior and Human Decision Processes, 67(1), 26-48. https://doi.org/10.1006/obhd.1996.0063.

Cain, M. K., Zhang, Z., \& Yuan, K. H. (2017). Univariate and multivariate skewness and kurtosis for measuring nonnormality: Prevalence, influence and estimation. Behavior Research Methods, 49(5), 1716-1735. https://doi.org/10.3758/s13428-016-0814-1.

Campion, M. A., Fink, A. A., Ruggeberg, B. J., Carr, L., Phillips, G. M., \& Odman, R. B. (2011). Doing competencies well: Best practices in competency modeling. Personnel Psychology, 64(1), 225-262. https://doi.org/10.1111/j.1744-6570.2010.01207.x.

Carmines, E. G., \& Zeller, R. A. (1979). Reliability and validity assessment. Newbury Park: Sage. https://doi.org/10.4135/9781412985642.

Cavanaugh, M. A., Boswell, W. R., Roehling, M. V., \& Boudreau, J. W. (2000). An empirical examination of self-reported work stress among US managers. Journal of Applied Psychology, 85(1), 65-74. https://doi.org/10.1037/0021-9010.85.1.65.

Cerasoli, C. P., Alliger, G. M., Donsbach, J. S., Mathieu, J. E., Tannenbaum, S. I., \& Orvis, K. A. (2018). Antecedents and outcomes of informal learning behaviors: A meta-analysis. Journal of Business and Psychology, 33(2), 203-230. https://doi.org/10.1007/s10869-017-9492-y.

Chan, D. C., \& Auster, E. (2003). Factors contributing to the professional development of reference librarians. Library \& Information Science Research, 25(3), 265-286. https://doi.org/10.1016/ S0740-8188(03)00030-6.

Choi, W., \& Jacobs, R. L. (2011). Influences of formal learning, personal learning orientation, and supportive learning environment on informal learning. Human Resource Development Quarterly, 22(3), 239-257. https://doi.org/10.1002/hrdq.20078.

Choi, W., Noe, R., \& Cho, Y. (2019). What is responsible for the psychological capital-job performance relationship? An examination of the role of informal learning and person-environment fit. Journal of Managerial Psychology, 35(1), 28-41. https://doi.org/10.1108/JMP-12-2018-0562. 
Clardy, A. (2018). 70-20-10 and the dominance of informal learning: A fact in search of evidence. Human Resource Development Review, 17(2), 153-178. https://doi.org/10.1177/1534484318 759399.

Coetzer, A., Kock, H., \& Wallo, A. (2017). Distinctive characteristics of small businesses as sites for informal learning. Human Resource Development Review, 16(2), 111-134. https://doi. org/10.1177/1534484317704291.

Cohen, J. (1988). Statistical power analysis for the behavioral sciences (2nd ed.). Hillsdale: Lawrence Erlbaum Associates.

Cohen, J., Cohen, P., West, S. G., \& Aiken, L. S. (2003). Applied multiple regression/correlation analysis for the behavioral sciences (3rd ed.). Mahwah: Lawrence Erlbaum.

Cole, D. A., \& Maxwell, S. E. (2003). Testing mediational models with longitudinal data: Questions and tips in the use of structural equation modeling. Journal of Abnormal Psychology, 112(4), 558. https://doi.org/10.1037/0021-843X.112.4.558.

Colquitt, J. A., LePine, J. A., \& Noe, R. A. (2000). Toward an integrative theory of training motivation: A meta-analytic path analysis of 20 years of research. Journal of Applied Psychology, 85(5), 678-707. https://doi.org/10.1037/0021-9010.85.5.678.

Cronbach, L., \& Snow, R. (1977). Aptitudes and instructional methods: A handbook for research on interactions. New York: Irvington.

Cropanzano, R., \& Mitchell, M. S. (2005). Social exchange theory: An interdisciplinary review. Journal of Management, 31(6), 874-900. https://doi.org/10.1177/0149206305279602.

Crouse, P., Doyle, W., \& Young, J. D. (2011). Workplace learning strategies, barriers, facilitators and outcomes: A qualitative study among human resource management practitioners. Human Resource Development International, 14(1), 39-55. https://doi.org/10.1080/13678 868.2011.542897.

Decius, J., \& Schaper, N. (2017). The competence management tool (CMT) - A new instrument to manage competences in small and medium-sized manufacturing enterprises. Procedia Manufacturing, 9, 376-383. https://doi.org/10.1016/j.promfg.2017.04.041.

Decius, J., Schaper, N., \& Seifert, A. (2019). Informal workplace learning: Development and validation of a measure. Human Resource Development Quarterly, 30(4), 495-535. https://doi.org/10.1002/ hrdq. 21368.

DeKeyser, R., \& Botana, G. P. (2019). Current research on instructed second language learning: A bird's eye view. In R. DeKeyser \& G. P. Botana, (Eds.), Doing SLA Research with Implications for the Classroom: Reconciling Methodological Demands and Pedagogical Applicability, 52, (pp. 1-8.). Amsterdam: John Benjamins. https://doi.org/10.1075/11lt.52.01dek.

Demerouti, E., Bakker, A. B., Nachreiner, F., \& Schaufeli, W. B. (2001). The job demandsresources model of burnout. Journal of Applied Psychology, 86(3), 499-512. https://doi. org/10.1037/0021-9010.86.3.499.

Disabato, D. (2016). The double standard against cross-sectional mediation. Applied Statistics Blog. Online available under http://www.daviddisabato.com/blog/2016/5/22/the-double-standard-again st-cross-sectional-mediation. Accessd 20 Nov 2020.

Döring, N., \& Bortz, J. (2016). Forschungsmethoden und evaluation in den Sozial- und Humanwissenschaften [research methods and evaluation in the social sciences and humanities]. Heidelberg: Springer. https://doi.org/10.1007/978-3-642-41089-5.

Dunn, T. J., Baguley, T., \& Brunsden, V. (2014). From alpha to omega: A practical solution to the pervasive problem of internal consistency estimation. British Journal of Psychology, 105(3), 399-412. https://doi.org/10.1111/bjop.12046.

Eby, L. T., Butts, M. M., Hoffman, B. J., \& Sauer, J. B. (2015). Cross-lagged relations between mentoring received from supervisors and employee OCBs: Disentangling causal direction and identifying boundary conditions. Journal of Applied Psychology, 100(4), 1275-1285. https://doi.org/10.1037/ a0038628.

Ellström, P. E. (2001). Integrating learning and work: Problems and prospects. Human Resource Development Quarterly, 12(4), 421-435. https://doi.org/10.1002/hrdq.1006.

Ellström, P. E. (2011). Informal learning at work: Conditions, processes and logics. In M. Malloch, L. Cairns, K. Evans, \& B. N. O'Connor (Eds.), The sage handbook of workplace learning (pp. 105119). London: Sage. https://doi.org/10.4135/9781446200940.n8.

Else Ouweneel, A. P., Taris, T. W., Van Zolingen, S. J., \& Schreurs, P. J. (2009). How task characteristics and social support relate to managerial learning: Empirical evidence from Dutch home care. The Journal of Psychology, 143(1), 28-44. https://doi.org/10.3200/JRLP.143.1.28-44. 
Enders, C. K. (2010). Applied missing data analysis. New York: Guilford Press.

European Union (2017). 2016 SBA fact sheet. Online available under https://ec.europa.eu/jrc/sites/jrcsh/ files/eu28_sba_fact_sheet.pdf. Accessed 20 Nov 2020

Farrell, A. M. (2010). Insufficient discriminant validity: A comment on Bove, Pervan, Beatty, and Shiu (2009). Journal of Business Research, 63(3), 324-327. https://doi.org/10.1016/j.jbusr es.2009.05.003.

Flaherty, E. G. (1975). The thinking aloud technique and problem solving ability. The Journal of Educational Research, 68(6), 223-225. https://doi.org/10.1080/00220671.1975.10884753.

Frese, M., \& Keith, N. (2015). Action errors, error management, and learning in organizations. Annual Review of Psychology, 66, 661-687. https://doi.org/10.1146/annurev-psych-010814-015205.

Froehlich, D. E. (2017). Older managers' informal learning in knowledge-intensive organizations: Investigating the role of learning approaches among Austrian bank managers. The International Journal of Human Resource Management, 28(2), 399-341. https://doi.org/10.1080/09585192.2016.12448 97.

Froehlich, D. E., Segers, M., \& Van den Bossche, P. (2014). Informal workplace learning in Austrian banks: The influence of learning approach, leadership style, and organizational learning culture on managers' learning outcomes. Human Resource Development Quarterly, 25(1), 29-57. https://doi. org/10.1002/hrdq. 21173 .

Froehlich, D. E., Beausaert, S., \& Segers, M. (2017). Development and validation of a scale measuring approaches to work-related informal learning. International Journal of Training and Development, 21(2), 130-144. https://doi.org/10.1111/ijtd.12099.

Gabriel, A. S., Podsakoff, N. P., Beal, D. J., Scott, B. A., Sonnentag, S., Trougakos, J. P., \& Butts, M. M. (2018). Experience sampling methods: A discussion of critical trends and considerations for scholarly advancement. Organizational Research Methods, 22(4), 969-1006. https://doi. org/10.1177/1094428118802626.

Galiläer, L., \& Wende, R. (2008). Früherkennung im Betrieb-Instrumente und Methoden zur Erhebung des aktuellen und zukünftigen Qualifikationsbedarfs [early detection in company instruments and methods for determining current and future qualification needs]. Qualifikationstrends-Erkennen, Aufbereiten, Transferieren. Wirtschaft und Bildung, 47, 81-106.

Gijbels, D., Raemdonck, I., \& Vervecken, D. (2010). Influencing work-related learning: The role of job characteristics and self-directed learning orientation in part-time vocational education. Vocations and Learning, 3(3), 239-255. https://doi.org/10.1007/s12186-010-9041-6.

Gijbels, D., Raemdonck, I., Vervecken, D., \& Van Herck, J. (2012). Understanding work-related learning: The case of ICT workers. Journal of Workplace Learning, 24(6), 416-429. https://doi. org/10.1108/13665621211250315.

Grace, J. B., \& Bollen, K. A. (2005). Interpreting the results from multiple regression and structural equation models. The Bulletin of the Ecological Society of America, 86(4), 283-295. https://doi. org/10.1890/0012-9623(2005)86[283:ITRFMR]2.0.CO;2.

Grosemans, I., Smet, K., Houben, E., de Cuyper, N., \& Kyndt, E. (2020). Development and validation of an instrument to measure work-related learning. Scandinavian Journal of Work and Organizational Psychology, 5(1), 1-16. https://doi.org/10.16993/sjwop.99.

Hackman, J. R., \& Oldham, G. R. (1980). Work Redesign. Reading: Addison-Wesley.

Hair, J. F., Black, W. C., Babin, B. J., \& Anderson, R. E. (2010). Multivariate data analysis: A global perspective (3rd ed.). Harlow: Pearson.

Harteis, C., Bauer, J., \& Gruber, H. (2008). The culture of learning from mistakes: How employees handle mistakes in everyday work. International Journal of Educational Research, 47(4), 223-231. https://doi.org/10.1016/j.ijer.2008.07.003.

Heggestad, E. D., Scheaf, D. J., Banks, G. C., Monroe Hausfeld, M., Tonidandel, S., \& Williams, E. B. (2019). Scale adaptation in organizational science research: A review and best-practice recommendations. Journal of Management, 45(6), 2596-2627. https://doi.org/10.1177/0149206319850280.

Hicks, E., Bagg, R., Doyle, W., \& Young, J. D. (2007). Canadian accountants: Examining workplace learning. Journal of Workplace Learning, 19(2), 61-77. https://doi.org/10.1108/136656207107284 57.

Hirsch-Kreinsen, H. \& ten Hompel, M. (2017). Digitalisierung industrieller Arbeit: Entwicklungsperspektiven und Gestaltungsansätze [Digitalization of Industrial Work: Development Perspectives and Design Approaches]. In B. Vogel-Heuser, T. Bauernhansl, \& M. ten Hompel (Eds.), Handbuch Industrie 4.0, Bd. 3 (pp. 357-376). Berlin: Springer Vieweg. https://doi.org/10.1007/978-3-66253251-5_21. 
Huang, T. P. (2011). Comparing motivating work characteristics, job satisfaction, and turnover intention of knowledge workers and blue-collar workers, and testing a structural model of the variables' relationships in China and Japan. The International Journal of Human Resource Management, 22(04), 924-944. https://doi.org/10.1080/09585192.2011.555134.

Hurtz, G. M., \& Williams, K. J. (2009). Attitudinal and motivational antecedents of participation in voluntary employee development activities. Journal of Applied Psychology, 94(3), 635-653. https:// doi.org/10.1037/a0014580.

Iacobucci, D. (2010). Structural equations modeling: Fit indices, sample size, and advanced topics. Journal of Consumer Psychology, 20(1), 90-98. https://doi.org/10.1016/j.jcps.2009.09.003.

Ilgen, D. R., Hollenbeck, J. R., Johnson, M., \& Jundt, D. (2005). Teams in organizations: From inputprocess-output models to IMOI models. Annual Review of Psychology, 56, 517-543. https://doi. org/10.1146/annurev.psych.56.091103.070250.

Illeris, K. (2006). Lifelong learning and the low-skilled. International Journal of Lifelong Education, 25(1), 15-28. https://doi.org/10.1080/02601370500309451.

Ittermann, P., Abel, J., \& Dostal, W. (2011). Industrielle Einfacharbeit-Stabilität und Perspektiven [lowskilled industrial work-stability and perspektives]. Arbeit, 20(3), 157-172. https://doi.org/10.1515/ arbeit-2011-0303.

Janssens, L., Smet, K., Onghena, P., \& Kyndt, E. (2017). The relationship between learning conditions in the workplace and informal learning outcomes: a study among police inspectors. International Journal of Training and Development, 21(2), 92-112. 92-112. https://doi.org/10.1111/ijtd.12095.

Jeon, K. S., \& Kim, K. N. (2012). How do organizational and task factors influence informal learning in the workplace? Human Resource Development International, 15(2), 209-226. https://doi. org/10.1080/13678868.2011.647463.

Jeong, S., Han, S. J., Lee, J., Sunalai, S., \& Yoon, S. W. (2018a). Integrative literature review on informal learning: Antecedents, conceptualizations, and future directions. Human Resource Development Review, 17(2), 128-152. https://doi.org/10.1177/1534484318772242.

Jeong, S., McLean, G. N., \& Park, S. (2018b). Understanding informal learning in small-and mediumsized enterprises in South Korea. Journal of Workplace Learning, 30(2), 89-107. https://doi. org/10.1108/jwl-03-2017-0028.

Karasek, R., \& Theorell, T. (1990). Healthy work: Stress, productivity and the reconstruction of working life. New York: Basic Books. https://doi.org/10.1016/0003-6870(92)90320-u.

Kashdan, T. B., Gallagher, M. W., Silvia, P. J., Winterstein, B. P., Breen, W. E., Terhar, D., \& Steger, M. F. (2009). The curiosity and exploration inventory-II: Development, factor structure, and psychometrics. Journal of Research in Personality, 43(6), 987-998. https://doi.org/10.1016/j. jrp.2009.04.011.

Klein, H. J., Noe, R. A., \& Wang, C. (2006). Motivation to learn and course outcomes: The impact of delivery mode, learning goal orientation, and perceived barriers and enablers. Personnel Psychology, 59(3), 665-702. https://doi.org/10.1111/j.1744-6570.2006.00050.x.

Kline, R. B. (2016). Principles and practice of structural equation modeling (4th ed.). New York: Guilford.

Kock, H., \& Ellström, P. E. (2011). Formal and integrated strategies for competence development in SMEs. Journal of European Industrial Training, 35(1), 71-88. https://doi.org/10.1108/03090 591111095745.

Kortsch, T., \& Kauffeld, S. (2019). Validation of a German version of the dimensions of the learning organization questionnaire (DLOQ) in German craft companies. Zeitschrift für Arbeits- und Organisationspsychologie A\&O, 63, 15-31. https://doi.org/10.1026/0932-4089/a000282.

Kortsch, T., Schulte, E.-M., \& Kauffeld, S. (2019). Learning@work: Informal learning strategies of German craft workers. European Journal of Training and Development, 43(5/6), 418-434. https://doi. org/10.1108/EJTD-06-2018-0052.

Kraiger, K., Ford, J. K., \& Salas, E. (1993). Application of cognitive, skill-based, and affective theories of learning outcomes to new methods of training evaluation. Journal of Applied Psychology, 78(2), 311-328. https://doi.org/10.1037/0021-9010.78.2.311.

Kronstad, M., \& Eide, M. (2015). How online journalists learn within a non-formal context. Journal of Workplace Learning, 27(3), 226-240. https://doi.org/10.1108/JWL-12-2013-0107.

Kyndt, E., \& Baert, H. (2013). Antecedents of employees' involvement in work-related learning: A systematic review. Review of Educational Research, 83(2), 273-313. https://doi.org/10.3102/00346 54313478021. 
Kyndt, E., Govaerts, N., Dochy, F., \& Baert, H. (2011). The learning intention of low-qualified employees: A key for participation in lifelong learning and continuous training. Vocations and Learning, 4(3), 211. https://doi.org/10.1007/s12186-011-9058-5.

Kyndt, E., Dochy, F., Onghena, P., \& Baert, H. (2013a). The learning intentions of low-qualified employees: A multilevel approach. Adult Education Quarterly, 63(2), 165-189. https://doi. org/10.1177/0741713612454324.

Kyndt, E., Govaerts, N., Claes, T., De La Marche, J., \& Dochy, F. (2013b). What motivates low-qualified employees to participate in training and development? A mixed-method study on their learning intentions. Studies in Continuing Education, 35(3), 315-336. https://doi.org/10.1080/01580 37X.2013.764282.

Kyndt, E., Onghena, P., Smet, K., \& Dochy, F. (2014). Employees' willingness to participate in workrelated learning: A multilevel analysis of employees' learning intentions. International Journal for Educational and Vocational Guidance, 14(3), 309-327. https://doi.org/10.1007/s1077 5-014-9272-4.

Kyndt, E., Gijbels, D., Grosemans, I., \& Donche, V. (2016a). Teachers' everyday professional development: Mapping informal learning activities, antecedents, and learning outcomes. Review of Educational Research, 86(4), 1111-1150. https://doi.org/10.3102/0034654315627864.

Kyndt, E., Vermeire, E., \& Cabus, S. (2016b). Informal workplace learning among nurses: Organisational learning conditions and personal characteristics that predict learning outcomes. Journal of Workplace Learning, 28(7), 435-450. https://doi.org/10.1108/JWL-06-2015-0052.

Landsbergis, P. A., Schnall, P. L., Deitz, D., Friedman, R., \& Pickering, T. (1992). The patterning of psychological attributes and distress by "job strain" and social support in a sample of working men. Journal of Behavioral Medicine, 15(4), 379-405. https://doi.org/10.1007/bf00844730.

Lauber, T. B., Taylor, E. J., Decker, D. J., \& Knuth, B. A. (2010). Challenges of professional development: Balancing the demands of employers and professions in federal natural resource agencies. Organization \& Environment, 23(4), 446-464. https://doi.org/10.1177/1086026610387760.

Lave, J., \& Wenger, E. (1991). Situated learning: Legitimate peripheral participation. Cambridge: Cambridge University Press. https://doi.org/10.1017/cbo9780511815355.

LePine, J. A., LePine, M. A., \& Jackson, C. L. (2004). Challenge and hindrance stress: Relationships with exhaustion, motivation to learn, and learning performance. Journal of Applied Psychology, 89(5), 883-891. https://doi.org/10.1037/0021-9010.89.5.883.

Little, T. D., Slegers, D. W., \& Card, N. A. (2006). A non-arbitrary method of identifying and scaling latent variables in SEM and MACS models. Structural Equation Modeling, 13(1), 59-72. https:// doi.org/10.1207/s15328007sem1301_3.

Locke, E. A., \& Latham, G. P. (1990). A theory of goal setting and task performance. Englewood Cliffs: Prentice-Hall.

Locke, E. A., \& Latham, G. P. (2002). Building a practically useful theory of goal setting and task motivation: A 35-year odyssey. American Psychologist, 57(9), 705-717. https://doi. org/10.1037/0003-066X.57.9.705.

Lodahl, T. M., \& Kejner, M. (1965). The definition and measurement of job involvement. Journal of Applied Psychology, 49(1), 24-33. https://doi.org/10.1037/h0021692.

Lohman, M. C. (2000). Environmental inhibitors to informal learning in the workplace: A case study of public school teachers. Adult Education Quarterly, 50(2), 83-101. https://doi.org/10.1177/07417 130022086928.

Lohman, M. C. (2005). A survey of factors influencing the engagement of two professional groups in informal workplace learning activities. Human Resource Development Quarterly, 16(4), 501-527. https://doi.org/10.1002/hrdq.1153.

Lohman, M. C. (2006). Factors influencing teachers' engagement in informal learning activities. Journal of Workplace Learning, 18(3), 141-156. https://doi.org/10.1108/13665620610654577.

Lundkvist, A. H., \& Gustavsson, M. (2018). Conditions for employee learning and innovation-interweaving competence development activities provided by a workplace development Programme with everyday work activities in SMEs. Vocations and Learning, 11(1), 45-63. https://doi.org/10.1007/ s12186-017-9179-6.

Marsh, H. W., Hau, K. T., \& Wen, Z. (2004). In search of golden rules: Comment on hypothesis-testing approaches to setting cutoff values for fit indexes and dangers in overgeneralizing Hu and Bentler's (1999) findings. Structural Equation Modeling, 11(3), 320-341. https://doi.org/10.1207/s1532 8007sem1103_2. 
Marsick, V. J., \& Volpe, M. (1999). The nature and need for informal learning. In V. J. Marsick \& M. Volpe (Eds.), Informal learning on the job (Advances in developing human resources, No. 3, pp. 1-9). Baton Rouge: Academy of Human Resource Development.

Matzler, K., \& Mueller, J. (2011). Antecedents of knowledge sharing-examining the influence of learning and performance orientation. Journal of Economic Psychology, 32(3), 317-329. https://doi. org/10.1016/j.joep.2010.12.006.

Maurer, T. J., Weiss, E. M., \& Barbeite, F. G. (2003). A model of involvement in work-related learning and development activity: The effects of individual, situational, motivational, and age variables. Journal of Applied Psychology, 88(4), 707-724. https://doi.org/10.1037/0021-9010.88.4.707.

Maxwell, S. E., \& Cole, D. A. (2007). Bias in cross-sectional analyses of longitudinal mediation. Psychological Methods, 12(1), 23-44. https://doi.org/10.1037/1082-989X.12.1.23.

Meade, A. W., \& Craig, S. B. (2012). Identifying careless responses in survey data. Psychological Methods, 17(3), 437. https://doi.org/10.1037/a0028085.

Mitchell, M. A., \& Maxwell, S. E. (2013). A comparison of the cross-sectional and sequential designs when assessing longitudinal mediation. Multivariate Behavioral Research, 48(3), 301-339. https:// doi.org/10.1080/00273171.2013.784696.

Moon, S. Y., \& Na, S. I. (2009). Psychological and organizational variables associated with workplace learning in small and medium manufacturing businesses in Korea. Asia Pacific Education Review, 10(3), 327-336. https://doi.org/10.1007/s12564-009-9040-1.

Nikolova, I., Van Ruysseveldt, J., De Witte, H., \& Van Dam, K. (2014). Learning climate scale: Construction, reliability and initial validity evidence. Journal of Vocational Behavior, 85(3), 258-265. https://doi.org/10.1016/j.jvb.2014.07.007.

Nikolova, I., Van Ruysseveldt, J., De Witte, H., \& Syroit, J. (2014a). Well-being in times of task restructuring: The buffering potential of workplace learning. Work \& Stress, 28(3), 217-235. https://doi.org/10.1080/02678373.2014.929601.

Nikolova, I., Van Ruysseveldt, J., De Witte, H., \& Syroit, J. (2014b). Work-based learning: Development and validation of a scale measuring the learning potential of the workplace (LPW). Journal of Vocational Behavior, 84(1), 1-10. https://doi.org/10.1016/j.jvb.2013.09.004.

Noe, R. A., Tews, M. J., \& Marand, A. D. (2013). Individual differences and informal learning in the workplace. Journal of Vocational Behavior, 83(3), 327-335. https://doi.org/10.1016/j. jvb.2013.06.009.

Noe, R. A., Clarke, A. D., \& Klein, H. J. (2014). Learning in the twenty-first-century workplace. Annual Review of Organizational Psychology and Organizational Behavior, 1(1), 245-275. https://doi.org/10.1146/annurev-orgpsych-031413-091321.

Noe, R. A., Tews, M. J., \& Michel, J. W. (2017). Managers' informal learning: A trait activation theory perspective. International Journal of Training and Development, 21(1), 1-17. https:// doi.org/10.1111/ijtd.12092.

Noordzij, G., Van Hooft, E. A., Van Mierlo, H., Van Dam, A., \& Born, M. P. (2013). The effects of a learning-goal orientation training on self-regulation: A field experiment among unemployed job seekers. Personnel Psychology, 66(3), 723-755. https://doi.org/10.1111/peps.12011.

Organ, D. W. (1988). Organizational citizenship behavior: The good soldier syndrome. Lexington: Lexington Books. https://doi.org/10.2307/2393071.

Orvis, K. A., \& Leffler, G. P. (2011). Individual and contextual factors: An interactionist approach to understanding employee self-development. Personality and Individual Differences, 51(2), 172177. https://doi.org/10.1016/j.paid.2011.03.038.

Parker, S. K. (2017). Work Design Growth Model: How work characteristics promote learning and development. In J. E. Ellingson \& R. A. Noe (Eds.), Autonomous Learning in the Workplace. (pp. 137-161), SIOP Frontiers Book Series. New York: Taylor \& Francis.

Pierce, H. R., \& Maurer, T. J. (2009). Linking employee development activity, social exchange and organizational citizenship behavior. International Journal of Training and Development, 13(3), 139-147. https://doi.org/10.1111/j.1468-2419.2009.00323.x.

Podsakoff, P. M., MacKenzie, S. B., Lee, J. Y., \& Podsakoff, N. P. (2003). Common method biases in behavioral research: A critical review of the literature and recommended remedies. Journal of Applied Psychology, 88(5), 879-903. https://doi.org/10.1037/0021-9010.88.5.879. 
Putz, D., Schilling, J., Kluge, A., \& Stangenberg, C. (2013). Measuring organizational learning from errors: Development and validation of an integrated model and questionnaire. Management Learning, 44(5), 511-536. https://doi.org/10.1177/1350507612444391.

R Core Team. (2019). R: A language and environment for statistical computing. Vienna: R Foundation for Statistical Computing.

Raemdonck, I., Gijbels, D., \& Van Groen, W. (2014a). The influence of job characteristics and selfdirected learning orientation on workplace learning. International Journal of Training and Development, 18(3), 188-203. https://doi.org/10.1111/ijtd.12028.

Raemdonck, I., Meurant, C., Balasse, J., Jacot, A., \& Frenay, M. (2014b). Exploring the concept of 'self-directedness in learning': Theoretical approaches and measurement in adult education literature. In D. Gijbels, D., V. Donche, J. T. E. Richardson \& J. D. Vermunt (Eds.), Learning patterns in higher education: Dimensions and research perspectives. New perspectives on learning and instruction (pp. 78-101). Routledge: London.

Rausch, A., Seifried, J., \& Harteis, C. (2017). Emotions, coping and learning in error situations in the workplace. Journal of Workplace Learning, 29(5), 374-393. https://doi.org/10.1108/ JWL-01-2017-0004.

Reio, T. G., \& Callahan, J. L. (2004). Affect, curiosity, and socialization-related learning: A path analysis of antecedents to job performance. Journal of Business and Psychology, 19(1), 3-22. https://doi.org/10.1023/B:JOBU.0000040269.72795.ce.

Reio, T. G., \& Wiswell, A. (2000). Field investigation of the relationship among adult curiosity, workplace learning, and job performance. Human Resource Development Quarterly, 11(1), 5-30. https://doi.org/10.1002/1532-1096(200021)11:1<5::AID-HRDQ2>3.0.CO;2-A.

Richter, P., Hemmann, E., Merboth, H., Fritz, S., Hänsgen, C., \& Rudolf, M. (2000). Das Erleben von Arbeitsintensität und Tätigkeitsspielraum-Entwicklung und Validierung eines Fragebogens zur orientierenden analyse (FIT) [the experience of intensity of labor and freedom of action-Development and validation of a questionnaire for oriented analysis]. Zeitschrift für Arbeits- und Organisationspsychologie, 44, 129-139. https://doi.org/10.1026//0932-4089.44.3.129.

Richter, S., Kortsch, T., \& Kauffeld, S. (2020). Understanding learning spillover: The major role of reflection in the formal-informal learning interaction within different cultural value settings. Journal of Workplace Learning, 32(7), 513-532. https://doi.org/10.1108/JWL-01-2020-0008.

Rosenshine, B., \& Furst, N. (1973). The use of direct observation to study teaching. In R. Travers (Ed.), Second handbook of research on teaching (pp. 122-183). Chicago: Rand McNally.

Rosseel, Y. (2012). lavaan. An R package for structural equation modeling. Journal of Statistical Software, 48, 1-36. https://doi.org/10.18637/jss.v048.i02.

Rouiller, J. Z., \& Goldstein, I. L. (1993). The relationship between organizational transfer climate and positive transfer of training. Human Resource Development Quarterly, 4(4), 377-390. https://doi. org/10.1002/hrdq.3920040408.

Rowold, J., \& Kauffeld, S. (2009). Effects of career-related continuous learning on competencies. Personnel Review, 38(1), 90-101. https://doi.org/10.1108/00483480910920732.

Rowold, J., \& Schilling, J. (2006). Career-related continuous learning: Longitudinal predictive power of employees' job and career attitudes. Career Development International, 11(6), 489-503. https:// doi.org/10.1108/13620430610692917.

Russ-Eft, D. (2002). A typology of training design and work environment factors affecting workplace learning and transfer. Human Resource Development Review, 1(1), 45-65. https://doi. org/10.1177/1534484302011003.

Rybowiak, V., Garst, H., Frese, M., \& Batinic, B. (1999). Error orientation questionnaire (EOQ): Reliability, validity, and different language equivalence. Journal of Organizational Behavior, 20(4), 527-547. https://doi.org/10.1002/(SICI)1099-1379(199907)20:4<527::AID-JOB886>3.0.CO;2-G.

Sanders, J., Oomens, S., Blonk, R. W., \& Hazelzet, A. (2011). Explaining lower educated workers' training intentions. Journal of Workplace Learning, 23(6), 402-416. https://doi.org/10.1108/13665 621111154412 .

Schmitz, B., \& Wiese, B. S. (2006). New perspectives for the evaluation of training sessions in self-regulated learning: Time-series analyses of diary data. Contemporary Educational Psychology, 31(1), 64-96. https://doi.org/10.1016/j.cedpsych.2005.02.002. 
Schulz, M., \& Stamov Roßnagel, C. S. (2010). Informal workplace learning: An exploration of age differences in learning competence. Learning and Instruction, 20(5), 383-399. https://doi.org/10.1016/j. learninstruc.2009.03.003.

Schürmann, E., \& Beausaert, S. (2016). What are drivers for informal learning? European Journal of Training and Development, 40(3), 130-154. https://doi.org/10.1108/EJTD-06-2015-0044.

Segers, M., Messmann, G., \& Dochy, F. (2018). Emergence, theoretical foundation, and conceptualisation of informal learning at work. In G. Messmann, M. Segers, \& F. Dochy (Eds.), Informal learning at work: Triggers, antecedents, and consequences (pp. 1-11). Oxon: Routledge. https://doi. org/10.4324/9781315441962-1.

Shin, T., Davison, M. L., \& Long, J. D. (2009). Effects of missing data methods in structural equation modeling with nonnormal longitudinal data. Structural Equation Modeling: A Multidisciplinary Journal, 16(1), 70-98. https://doi.org/10.1080/10705510802569918.

Shrout, P. E., \& Bolger, N. (2002). Mediation in experimental and nonexperimental studies: New procedures and recommendations. Psychological Methods, 7(4), 422-445. https://doi. org/10.1037/1082-989x.7.4.422.

Silvia, P. J. (2006). Exploring the psychology of interest. New York: Oxford University Press. https://doi. org/10.1093/acprof:oso/9780195158557.001.0001.

Skule, S. (2004). Learning conditions at work: A framework to understand and assess informal learning in the workplace. International Journal of Training and Development, 8(1), 8-20. https://doi.org/1 0.1111/j.1360-3736.2004.00192.x.

Somech, A., \& Drach-Zahavy, A. (2004). Exploring organizational citizenship behaviour from an organizational perspective: The relationship between organizational learning and organizational citizenship behaviour. Journal of Occupational and Organizational Psychology, 77(3), 281-298. https:// doi.org/10.1348/0963179041752709.

Sonntag, K., Schaper, N., \& Friebe, J. (2005). Erfassung und Bewertung von Merkmalen unternehmensbezogener Lernkulturen [Assessment and evaluation of characteristics of company-related learning cultures]. In Arbeitsgemeinschaft Betriebliche Weiterbildungsforschung e. V. / Projekt Qualifikations-Entwicklungs-Management (Ed.), Kompetenzmessung im Unternehmen. Lernkultur- und Kompetenzanalysen im betrieblichen Umfeld (pp. 19-339). Münster, New York, München, Berlin: Waxmann.

Spector, P. E. (2019). Do not cross me: Optimizing the use of cross-sectional designs. Journal of Business and Psychology, 34(2), 125-137. https://doi.org/10.1007/s10869-018-09613-8.

Spreitzer, G. M., McCall, M. W., \& Mahoney, J. D. (1997). Early identification of international executive potential. Journal of Applied Psychology, 82(1), 6-29. https://doi.org/10.1037/0021-9010.82.1.6.

Stone-Romero, E. F., \& Rosopa, P. J. (2008). The relative validity of inferences about mediation as a function of research design characteristics. Organizational Research Methods, 11(2), 326-352. https://doi.org/10.1177/1094428107300342.

Susomrith, P., \& Coetzer, A. (2019). Effects of informal learning on work engagement. Personnel Review, 48(7), 1886-1902. https://doi.org/10.1108/PR-10-2018-0430.

Svensson, L., Ellström, P. E., \& Åberg, C. (2004). Integrating formal and informal learning at work. Journal of Workplace Learning, 16(8), 479-491. https://doi.org/10.1108/13665620410566441.

Tannenbaum, S. I., Beard, R. L., McNall, L. A., \& Salas, E. (2010). Informal learning and development in organizations. In S. W. J. Kozlowski \& E. Salas (Eds.), Learning, training, and development in organizations (pp. 303-332). New York: Routledge.

Taris, T. W., Kompier, M. A., De Lange, A. H., Schaufeli, W. B., \& Schreurs, P. J. (2003). Learning new behaviour patterns: A longitudinal test of Karasek's active learning hypothesis among Dutch teachers. Work \& Stress, 17(1), 1-20. https://doi.org/10.1080/0267837031000108149.

Tippelt, R., Reich, J., \& Panyr, S. (2004). Teilnehmer- und milieuspezifische Aspekte der Weiterbildungsbeteiligung [participant and environment-specific aspects of continuing education participation]. Report, 27(3), 48-56.

Toppinen-Tanner, S., Kalimo, R., \& Mutanen, P. (2002). The process of burnout in white-collar and bluecollar jobs: Eight-year prospective study of exhaustion. Journal of Organizational Behavior: The International Journal of Industrial, Occupational and Organizational Psychology and Behavior, 23(5), 555-570. https://doi.org/10.1002/job.155. 
Tynjälä, P. (2013). Toward a 3-P model of workplace learning: A literature review. Vocations and Learning, 6(1), 11-36. https://doi.org/10.1007/s12186-012-9091-z.

Van der Heijden, B., Boon, J., Van der Klink, M., \& Meijs, E. (2009). Employability enhancement through formal and informal learning: An empirical study among Dutch non-academic university staff members. International Journal of Training and Development, 13(1), 19-37. https://doi.org/1 0.1111/j.1468-2419.2008.00313.x.

Van der Klink, M., Van der Heijden, B., Boon, J., \& Williams Van Rooij, S. (2014). Exploring the contribution of formal and informal learning to academic staff member employability: A Dutch perspective. Career Development International, 19(3), 337-356. https://doi.org/10.1108/ CDI-03-2013-0030.

Van Doorn, Y., Van Ruysseveldt, J., Van Dam, K., Mistiaen, W., \& Nikolova, I. (2016). Understanding well-being and learning of Nigerian nurses: A job demand control support model approach. Journal of Nursing Management, 24(7), 915-922. https://doi.org/10.1111/jonm.12397

Van Dyck, C., Frese, M., Baer, M., \& Sonnentag, S. (2005). Organizational error management culture and its impact on performance: A two-study replication. Journal of Applied Psychology, 90(6), 1228. https://doi.org/10.1037/0021-9010.90.6.1228

Van Ruysseveldt, J., \& Van Dijke, M. (2011). When are workload and workplace learning opportunities related in a curvilinear manner? The moderating role of autonomy. Journal of Vocational Behavior, 79(2), 470-483. https://doi.org/10.1016/j.jvb.2011.03.003

VandeWalle, D. (1997). Development and validation of a work domain goal orientation instrument. Educational and Psychological Measurement, 57(6), 995-1015. https://doi.org/10.1177/0013164497 057006009.

VandeWalle, D. (2003). A goal orientation model of feedback-seeking behavior. Human Resource Management Review, 13(4), 581-604. https://doi.org/10.1016/j.hrmr.2003.11.004.

Weston, R., \& Gore Jr., P. A. (2006). A brief guide to structural equation modeling. The Counseling Psychologist, 34(5), 719-751. https://doi.org/10.1177/0011000006286345.

Weststar, J. (2009). Worker control and workplace learning: Expansion of the job demand-control model. Industrial Relations: A Journal of Economy and Society, 48(3), 533-548. https://doi.org/10.1111/ j.1468-232X.2009.00572.x.

White, J. P., Armstrong, H., Armstrong, P., Bourgeault, I., Choiniere, J., \& Mykhalovskiy, E. (2000). The impact of managed care on nurses' workplace learning and teaching. Nursing Inquiry, 7(2), 74-80. https://doi.org/10.1046/j.1440-1800.2000.00060.x.

Williams, L. J., \& Anderson, S. E. (1991). Job satisfaction and organizational commitment as predictors of organizational citizenship and in-role behaviors. Journal of Management, 17(3), 601-617. https ://doi.org/10.1177/014920639101700305.

Willis, G. B. (2005). Cognitive interviewing: A tool for improving questionnaire design. Thousand Oaks: Sage.

Wolak, M. E., Fairbairn, D. J., \& Paulsen, Y. R. (2012). Guidelines for estimating repeatability. Methods in Ecology and Evolution, 3(1), 129-137. https://doi.org/10.1111/j.2041-210X.2011.00125.x.

Wolfson, M. A., Tannenbaum, S. I., Mathieu, J. E., \& Maynard, M. T. (2018). A cross-level investigation of informal field-based learning and performance improvements. Journal of Applied Psychology, 103(1), 14-36. https://doi.org/10.1037/ap10000267.

Wong, K. Y., \& Aspinwall, E. (2004). Characterizing knowledge management in the small business environment. Journal of Knowledge Management, 8(3), 44-61. https://doi.org/10.1108/1367327041 0541033.

Zhao, B. (2011). Learning from errors: The role of context, emotion, and personality. Journal of Organizational Behavior, 32(3), 435-463. https://doi.org/10.1002/job.696.

Zhao, B., Seifried, J., \& Sieweke, J. (2018). Trainers' responses to errors matter in trainees' learning from errors: Evidence from two studies. Journal of Managerial Psychology, 33(3), 279-296. https://doi. org/10.1108/JMP-10-2017-0364.

Publisher's Note Springer Nature remains neutral with regard to jurisdictional claims in published maps and institutional affiliations. 
Julian Decius is post-doctoral researcher at the Chair of Work and Organizational Psychology, University of Paderborn. His research interests focus on informal learning in the workplace and during studies, strategic competence development in small and medium-sized enterprises, (further) vocational education in the context of "Work 4.0" / new work, as well as competence assessment and development of professional soccer players.

Niclas Schaper is full professor and holder of the Chair of Work and Organizational Psychology, University of Paderborn. His research focuses on questions of competence acquisition, competence measurement and competence management in work- and occupation-related learning. In addition, he works on strategic and methodological issues of personnel and organizational development.

Andreas Seifert is post-doctoral researcher at the Center of Educational Research and Teacher Education, University of Paderborn. His fields of research are psychometric model building as well as modeling and measuring competencies in teacher education. Furthermore, he is interested in the action-oriented design of methods and statistics lectures and the evaluation of such lectures. 